NBER WORKING PAPER SERIES

\title{
VALUE VERSUS GROWTH: \\ TIME-VARYING EXPECTED STOCK RETURNS
}

\author{
Huseyin Gulen \\ Yuhang Xing \\ Lu Zhang \\ Working Paper 15993 \\ http://www.nber.org/papers/w15993 \\ NATIONAL BUREAU OF ECONOMIC RESEARCH
1050 Massachusetts Avenue
Cambridge, MA 02138
}

May 2010

For helpful comments, we thank Murray Carlson (AFA discussant), Sreedhar Bharath, Amy Dittmar, Evan Dudley, Philip Joos, Solomon Tadesse, Joanna Wu, and seminar participants at the American Finance Association Annual Meetings. Bill Christie (the Editor) and two anonymous referees deserve special thanks. This paper supersedes our previous work under the title "Value versus growth: Movements in economic fundamentals." The views expressed herein are those of the authors and do not necessarily reflect the views of the National Bureau of Economic Research.

NBER working papers are circulated for discussion and comment purposes. They have not been peerreviewed or been subject to the review by the NBER Board of Directors that accompanies official NBER publications.

(C) 2010 by Huseyin Gulen, Yuhang Xing, and Lu Zhang. All rights reserved. Short sections of text, not to exceed two paragraphs, may be quoted without explicit permission provided that full credit, including $\odot$ notice, is given to the source. 
Value versus Growth: Time-Varying Expected Stock Returns

Huseyin Gulen, Yuhang Xing, and Lu Zhang

NBER Working Paper No. 15993

May 2010

JEL No. G11,G12,G14

\section{ABSTRACT}

Is the value premium predictable? We study time-variations of the expected value premium using a two-state Markov switching model. We find that when conditional volatilities are high, the expected excess returns of value stocks are more sensitive to aggregate economic conditions than the expected excess returns of growth stocks. As a result, the expected value premium is time-varying: it spikes upward in the high-volatility state, only to decline more gradually in the ensuring periods. However, out-of-sample predictability of the value premium is close to nonexistent.

Huseyin Gulen

Krannert Graduate School of Management Purdue University

403 W. State Street

West Lafayette

IN 47907

hgulen@purdue.edu
Lu Zhang

Stephen M. Ross School of Business

University of Michigan

701 Tappan Street, R 4336

Ann Arbor, MI 48109-1234

and NBER

zhanglu@bus.umich.edu

Yuhang Xing

Jones School of Management, MS 531

Rice University

6100 Main Street

Houston, TX 77004

yxing@ rice.edu 


\section{Introduction}

We study time-variations of the expected value premium using a two-state Markov switching framework with time-varying transition probabilities. In contrast to predictive regressions, in which the intercept, the slopes, and the residual volatility are all constant, the nonlinear Markov switching framework allows these estimates to vary with a single latent state variable.

The nonlinear econometric framework delivers several fresh insights. First, in the high-volatility state the expected excess returns of value stocks are most sensitive, and the expected excess returns of growth stocks are least sensitive to worsening aggregate economic conditions. For example, in bivariate estimation in which we fit the Markov switching model on the value and growth portfolio returns jointly, the loading of the value portfolio on the default spread in the high-volatility state is $7.76(t=6.02)$, which is higher than the loading of the growth portfolio on the default spread, $4.60(t=3.33)$. In contrast, in the low-volatility state both the value and growth portfolios have insignificant loadings on the default spread: $1.29(t=1.67)$ and $1.06(t=1.47)$, respectively. A likelihood ratio test strongly rejects the null that the loading difference across the two states for the value portfolio equals the loading difference across the two states for the growth portfolio.

Second, the expected value premium exhibits clear time-variations: it tends to spike upward rapidly in the high-volatility state, only to decline more gradually in the ensuing periods. From January 1954 to December 2007, the expected value premium is on average 0.39\% per month (which is more than 14 standard errors from zero), and is positive for 472 out of 648 months (about $73 \%$ of the time). Conditional on being in the high-volatility state, expected one-year ahead returns for the value decile are substantially higher than those for the growth decile: $11.21 \%$ versus $-1.17 \%$ per annum. Conditional on being in the low-volatility state, expected one-year ahead returns are comparable for the two portfolios: $10.90 \%$ versus $10.26 \%$. There are also similar time-variations in the conditional volatility and the conditional Sharpe ratio of the value-minus-growth portfolio. However, out-of-sample predictability of the value premium is close to nonexistent. 
Third, we show that the nonlinearity embedded in the Markov switching framework is important for capturing the time-variations of the expected value premium. The nonlinear framework explains more time-variations in the expected value premium when the economy switches back and forth between the latent states. By construction, such jumps are ruled out by predictive regressions. When we estimate the expected value premium from predictive regressions, we find that unlike the Markov switching model, linear regressions fail to capture the upward spike of the expected value premium in the early 2000s. The time-variations captured by predictive regressions in other high-volatility periods are also substantially weaker than those from the Markov switching model.

Our econometric framework follows that of Perez-Quiros and Timmermann (2000). ${ }^{1}$ Our work differs in both economic question and theoretical motivation. Perez-Quiros and Timmermann ask whether there exists a differential response in expected returns to shocks to monetary policy between small and large firms. Their study is motivated by imperfect capital markets theories (e.g., Bernanke and Gertler (1989); Gertler and Gilchrist (1994); Kiyotaki and Moore (1997)). In contrast, we ask whether there exists a differential response in expected returns to shocks to aggregate economic conditions between value and growth firms. Our study is motivated by investment-based asset pricing theories (e.g., Cochrane (1991); Berk, Green, and Naik (1999); Zhang (2005)).

We are not the first to study whether the value premium is predictable. Prior studies have documented some suggestive evidence using predictive regressions (e.g., Jagannathan and Wang (1996); Pontiff and Schall (1999); Lettau and Ludvigson (2001); Cohen, Polk, and Vuolteenaho (2003)). However, the issue remains controversial. Lewellen and Nagel (2006) argue that the covariance between value-minus-growth risk and the aggregate risk premium is too small, meaning no time-variations in the expected value premium. Chen, Petkova, and Zhang (2008) show that the expected value premium estimated from predictive regressions is only weakly responsive to shocks to aggregate economic conditions. We add to the literature by using a different econometric framework.

\footnotetext{
${ }^{1}$ Similar regime switching models have been used extensively to address diverse issues such as international asset allocation (e.g., Ang and Bekaert (2002a); Guidolin and Timmermann (2008a)), interest rate dynamics (e.g., Ang and Bekaert (2002b)), capital markets integration (e.g., Bekaert and Harvey (1995)), and the joint distribution of stock and bond returns (e.g., Guidolin and Timmermann (2006); Guidolin and Timmermann (2008b)).
} 
The rest of the paper is organized as follows. Section 2 estimates a univariate Markov switching model for each of the ten book-to-market deciles. Section 3 estimates a bivariate Markov switching model for the value and growth deciles jointly. Section 4 concludes.

\section{A Univariate Model of Time-Varying Expected Stock Returns}

We describe our econometric framework in Section 2.1, our data and model specifications in Section 2.2, and our estimation results in Section 2.3.

\subsection{The Econometric Framework}

We adopt the Perez-Quiros and Timmermann (2000) Markov switching framework with timevarying transition probabilities based on prior work of Hamilton (1989) and Gray (1996). The Markov switching framework allows for state dependence in expected stock returns. For parsimony, we allow for only two possible states.

Let $r_{t}$ denote the excess return of a testing portfolio over period $t$ and $\mathbf{X}_{t-1}$ be a vector of conditioning variables. The Markov switching framework allows the intercept term, slope coefficients, and volatility of excess returns to depend on a single, latent state variable, $S_{t}$ :

$$
r_{t}=\beta_{0, S_{t}}+\boldsymbol{\beta}_{S_{t}}^{\prime} \mathbf{X}_{t-1}+\epsilon_{t} \quad \text { with } \quad \epsilon_{t} \sim \mathcal{N}\left(0, \sigma_{S_{t}}^{2}\right)
$$

in which $\mathcal{N}\left(0, \sigma_{S_{t}}^{2}\right)$ is a normal distribution with a mean of zero and a variance of $\sigma_{S_{t}}^{2}$. Two states, $S_{t}=1$ or 2 , mean that the slopes and variance are either $\left(\beta_{0,1}, \boldsymbol{\beta}_{1}^{\prime}, \sigma_{1}^{2}\right)$ or $\left(\beta_{0,2}, \boldsymbol{\beta}_{2}^{\prime}, \sigma_{2}^{2}\right)$.

To specify how the underlying state evolves through time, we assume that the state transition probabilities follow a first-order Markov chain:

$$
\begin{aligned}
p_{t} & =P\left(S_{t}=1 \mid S_{t-1}=1, \mathbf{Y}_{t-1}\right)=p\left(\mathbf{Y}_{t-1}\right) \\
1-p_{t} & =P\left(S_{t}=2 \mid S_{t-1}=1, \mathbf{Y}_{t-1}\right)=1-p\left(\mathbf{Y}_{t-1}\right) \\
q_{t} & =P\left(S_{t}=2 \mid S_{t-1}=2, \mathbf{Y}_{t-1}\right)=q\left(\mathbf{Y}_{t-1}\right) \\
1-q_{t} & =P\left(S_{t}=1 \mid S_{t-1}=2, \mathbf{Y}_{t-1}\right)=1-q\left(\mathbf{Y}_{t-1}\right)
\end{aligned}
$$


in which $\mathbf{Y}_{t-1}$ is a vector of variables publicly known at time $t-1$ and affects the state transition probabilities between time $t-1$ and $t$. Prior studies have shown that the state transition probabilities are time-varying and depend on prior conditioning information such as the economic leading indicator (e.g., Filardo (1994); Perez-Quiros and Timmermann (2000)) or interest rates (e.g., Gray (1996)). Intuitively, investors are likely to possess more superior information on the state transition probabilities than that implied by the model with constant transition probabilities.

We estimate the parameters of the econometric model using maximum likelihood methods. Let $\boldsymbol{\theta}$ denote the vector of parameters entering the likelihood function for the data. Suppose the density of the innovations, $\epsilon_{t}$, conditional on being in state $j, f\left(r_{t} \mid S_{t}=j, \mathbf{X}_{t-1} ; \boldsymbol{\theta}\right)$, is Gaussian:

$$
f\left(r_{t} \mid \Omega_{t-1}, S_{t}=j ; \boldsymbol{\theta}\right)=\frac{1}{\sqrt{2 \pi \sigma_{j}}} \exp \left(\frac{-\left(r_{t}-\beta_{0, j}-\boldsymbol{\beta}_{j}^{\prime} \mathbf{X}_{t-1}\right)^{2}}{2 \sigma_{j}}\right)
$$

for $j=1,2 . \Omega_{t-1}$ denotes the information set that contains $\mathbf{X}_{t-1}, r_{t-1}, \mathbf{Y}_{t-1}$, and lagged values of these variables. The log-likelihood function is given by:

$$
\mathcal{L}\left(r_{t} \mid \Omega_{t-1} ; \boldsymbol{\theta}\right)=\sum_{t=1}^{T} \log \left(\phi\left(r_{t} \mid \Omega_{t-1} ; \boldsymbol{\theta}\right)\right)
$$

in which the density, $\phi\left(r_{t} \mid \Omega_{t-1} ; \boldsymbol{\theta}\right)$, is obtained by summing the probability-weighted state densities, $f(\cdot)$, across the two possible states:

$$
\phi\left(r_{t} \mid \Omega_{t-1} ; \boldsymbol{\theta}\right)=\sum_{j=1}^{2} f\left(r_{t} \mid \Omega_{t-1}, S_{t}=j ; \boldsymbol{\theta}\right) P\left(S_{t}=j \mid \Omega_{t-1} ; \boldsymbol{\theta}\right)
$$

and $P\left(S_{t}=j \mid \Omega_{t-1} ; \boldsymbol{\theta}\right)$ is the conditional probability of state $j$ at time $t$ given information at $t-1$.

The conditional state probabilities can be obtained recursively:

$$
P\left(S_{t}=i \mid \Omega_{t-1} ; \boldsymbol{\theta}\right)=\sum_{j=1}^{2} P\left(S_{t}=i \mid S_{t-1}=j, \Omega_{t-1} ; \boldsymbol{\theta}\right) P\left(S_{t-1}=j \mid \Omega_{t-1} ; \boldsymbol{\theta}\right),
$$

in which the conditional state probabilities, by Bayes's rule, can be obtained as:

$$
P\left(S_{t-1}=j \mid \Omega_{t-1} ; \boldsymbol{\theta}\right)=\frac{f\left(r_{t-1} \mid S_{t-1}=j, \mathbf{X}_{t-1}, \mathbf{Y}_{t-1}, \Omega_{t-2} ; \boldsymbol{\theta}\right) P\left(S_{t-1}=j \mid \mathbf{X}_{t-1}, \mathbf{Y}_{t-1}, \Omega_{t-2} ; \boldsymbol{\theta}\right)}{\sum_{j=1}^{2} f\left(r_{t-1} \mid S_{t-1}=j, \mathbf{X}_{t-1}, \mathbf{Y}_{t-1}, \Omega_{t-2} ; \boldsymbol{\theta}\right) P\left(S_{t-1}=j \mid \mathbf{X}_{t-1}, \mathbf{Y}_{t-1}, \Omega_{t-2} ; \boldsymbol{\theta}\right)}
$$


Following Gray (1996) and Perez-Quiros and Timmermann (2000), we iterate on equations (9) and (10) to derive the state probabilities, $P\left(S_{t}=j \mid \Omega_{t-1} ; \boldsymbol{\theta}\right)$, and obtain the parameter estimates of the likelihood function. Evidence on the variations in the state probabilities can be interpreted as indicating time-variations in expected stock returns.

\subsection{Data and Model Specifications}

We use as testing assets the excess returns of the book-to-market deciles. Excess returns are defined in excess of the one-month Treasury bill rate. The data for the decile returns and Treasury bill rates are from Kenneth French's Web site. The sample period is from January 1954 to December 2007 with a total of 648 monthly observations. Following Perez-Quiros and Timmermann (2000), we start the sample from January 1954 to conform with the period after the Treasury-Federal Reserve Accord that allows the Treasury bill rates to vary freely. The mean monthly excess returns of the book-to-market deciles increase from $0.48 \%$ per month for the growth decile to $0.97 \%$ for the value decile. The value-minus-growth portfolio earns an average return of $0.48 \%$ with a volatility of $4.28 \%$ per month, meaning that the average return is more than 2.8 standard errors from zero.

We model the excess returns for each of the book-to-market portfolios as a function of an intercept term and lagged values of the one-month Treasury bill rate, the default spread, changes in the money stock, and the dividend yield. All the variables are common predictors of stock market excess returns. We use the one-month Treasury bill rate, $T B$, as a state variable to proxy for the unobserved expectations of investors on future economic activity. The Federal Reserve typically raises short-term interest rates in expansions to curb inflation and lowers short-term interest rates in recessions to stimulate economic growth. As such, the one-month Treasury bill rate is a common predictor for stock market returns (e.g., Fama and Schwert (1977); Fama (1981); Campbell (1987)).

The default spread, $D E F$, is the difference between yields on Baa- and Aaa-rated corporate bonds from Ibbotson Associates. Value firms are likely more exposed to bankruptcy risks during recessions than growth firms, meaning that the returns of value stocks should load more on the default 
spread than the returns of growth stocks. Also, the empirical macroeconomics literature shows that the default spread is one of the strongest business cycle forecasters (e.g., Stock and Watson (1989); Bernanke (1990)). Not surprisingly, the default spread has been used as a primary conditioning variable in predicting stock market returns (e.g., Keim and Stambaugh (1986); Fama and French (1989)). Indeed, Jagannathan and Wang (1996) use the default spread as the only instrument in modeling the expected market risk premium in their influential study of the conditional CAPM.

The growth in the money stock, $\Delta M$, is the 12-month log difference in the monetary base from the Federal Reserve Bank in St. Louis. We use the growth in the money supply to measure the liquidity changes in the economy as well as monetary policy shocks that can affect aggregate economic conditions. The dividend yield, $D I V$, is the dividends on the value-weighted CRSP market portfolio over the previous 12 months divided by the stock price at the end of the month. A popular conditioning variable (e.g., Campbell and Shiller (1988)), the dividend yield captures mean reversion in expected returns because a high dividend yield means that dividends are discounted at a higher rate.

For each book-to-market decile, indexed by $i$, we estimate the following model:

$$
r_{t}^{i}=\beta_{0, S_{t}}^{i}+\beta_{1, S_{t}}^{i} T B_{t-1}+\beta_{2, S_{t}}^{i} D E F_{t-1}+\beta_{3, S_{t}}^{i} \Delta M_{t-2}+\beta_{4, S_{t}}^{i} D I V_{t-1}+\epsilon_{t}^{i},
$$

in which $r_{t}^{i}$ is the monthly excess return for the $i^{\text {th }}$ book-to-market decile, $\epsilon_{t}^{i} \sim N\left(0, \sigma_{i, S_{t}}^{2}\right)$, and $S_{t}=\{1,2\}$. Following Perez-Quiros and Timmermann (2000), we lag the one-month Treasury bill rate, the default spread, and the dividend yield by one month, but the growth in money supply by two months to allow for the publication delay for this variable. The conditional variance of excess returns, $\sigma_{i, S_{t}}^{2}$ is allowed to depend on the state of the economy:

$$
\log \left(\sigma_{i, S_{t}}^{2}\right)=\lambda_{S_{t}}^{i}
$$

For parsimony, we do not include $\mathrm{ARCH}$ terms or instrumental variables in the volatility equation. 
State transition probabilities are specified as follows:

$$
\begin{aligned}
p_{t}^{i} & =P\left(S_{t}^{i}=1 \mid S_{t-1}^{i}=1, \mathbf{Y}_{t-1}\right)=\Phi\left(\pi_{0}^{i}+\pi_{1}^{i} T B_{t-1}\right) ; \\
1-p_{t}^{i} & =P\left(S_{t}^{i}=2 \mid S_{t-1}^{i}=1\right) ; \\
q_{t}^{i} & =P\left(S_{t}^{i}=2 \mid S_{t-1}^{i}=2, \mathbf{Y}_{t-1}\right)=\Phi\left(\pi_{0}^{i}+\pi_{2}^{i} T B_{t-1}\right) ; \\
1-q_{t}^{i} & =P\left(S_{t}^{i}=1 \mid S_{t-1}^{i}=2\right) ;
\end{aligned}
$$

in which $S_{t}^{i}$ is the state indictor for the $i^{\text {th }}$ portfolio and $\Phi$ is the cumulative density function of a standard normal variable. Following Gray (1996), we capture the information of investors on state transition probabilities through the use of the one-month Treasury bill rate.

\subsection{Estimation Results}

\subsubsection{The Interpretation of the States}

Table 1 shows that state 1 is associated with high conditional volatilities and that state 2 is associated with low conditional volatilities. As such, we interpret state 1 as the high-volatility state and state 2 as the low-volatility state. All book-to-market deciles have volatilities in the high-volatility state that are about twice as large as those in the low-volatility state. The difference in volatilities between the two states is largely similar in magnitude across the ten deciles. All the volatilities are estimated precisely with small standard errors.

Panels A and B in Figure 1 plot the conditional transition probabilities of being in the highvolatility state at time $t$ conditional on the information set at time $t-1, P\left(S_{t}=1 \mid \Omega_{t-1} ; \boldsymbol{\theta}\right)$, for the value and growth portfolios, respectively. We also overlay the transition probabilities with historical NBER recession dates. The conditional transition probabilities depend on lagged conditioning information and reflect the perception of investors on the conditional likelihood of being in the high-volatility state in the next period. The figure shows that the transitional probabilities of being in the high-volatility state are all fairly high during the eight post-war recessions. This evidence indicates that the high-volatility state is more likely in recessions and the low-volatility state 
is more likely in expansions. This link between stock volatilities and business cycles is consistent with the evidence of Schwert (1989) and Campbell, Lettau, Malkiel, and Xu (2001).

However, there are important caveats with identifying state 1 as recessions and state 2 as expansions. From Panels A and B in Figure 1, the frequency of the probability of being in state 1 spiking up to 0.90 is higher than the frequency of the aggregate economy entering a recession. In particular, state 1 also captures times of high stock return volatilities such as October 1987, which is not in a recession. From Panel B, the univariate Markov switching model also classifies the second half of the 1990s as a recession for the growth portfolio, even though this period has been one of the biggest booms for growth firms. This counterintuitive pattern is mostly driven by the high volatilities of growth firms during this period, and largely disappears in the bivariate Markov switching model, in which we estimate the state probabilities using both value and growth portfolio returns (see Section 3.2). In view of these caveats, we only interpret state 1 as the high-volatility state (as opposed to the recession state) and state 2 as the low-volatility state (as opposed to the expansion state).

\subsubsection{Conditional Mean Equations}

Our focus is on the conditional mean equations. Table 1 shows that coefficients on the one-month Treasury bill rate are all negative for the ten book-to-market deciles in the high-volatility state. All the coefficients are significant at the $5 \%$ level. More important, the magnitude of the coefficients varies systematically with book-to-market. Moving from growth to value, the coefficients increase in magnitude virtually monotonically from -5.68 (standard error $=1.54)$ to -11.67 (standard error $=$ 3.28). This evidence means that in the high-volatility state, value firms are more affected by interest rate shocks than growth firms. In contrast, in the low-volatility state the excess returns of the book-to-market portfolios are not much affected by the short-term interest rates. Although all the coefficients on the Treasury bill rate are negative, only three out of ten are significant. In particular, the coefficient for the growth portfolio is -1.45 , which is even slightly higher in magnitude than that for the value portfolio, -1.34 . Both coefficients are within 1.2 standard errors of zero. 
There are also systematic variations in the slopes of the portfolio excess returns on the default spread. In the high-volatility state, all the deciles generate coefficients of the default spread that are positive and significant at the $5 \%$ level. Moving from growth to value, the coefficient increases virtually monotonically from $4.02($ standard error $=0.88)$ to $7.31($ standard error $=1.79)$. However, in the low-volatility state, none of the ten estimated coefficients on the default spread are significant, although nine out of ten remain positive. There is some evidence that growth responds more to the default premium than value in the low-volatility state. The coefficient of the growth decile in the low-volatility state is 1.77 (standard error $=0.96$ ), and the coefficient of the value decile is only 0.38 (standard error $=0.62)$. On balance, however, the evidence suggests that the default spread mainly affects the expected returns in the high-volatility state and particularly for value firms.

The coefficients on the growth in money supply are not significant in our specification. These coefficients are all positive in the high-volatility state, meaning that higher monetary growth is related to higher expected returns. A possible explanation is that the Federal Reserve increases the money supply in bad times, during which the expected excess returns of the testing portfolios are higher. Turning to the coefficients on the dividend yield, we observe that in the high-volatility state, the coefficient for the growth decile is positive but insignificant, 0.22 with a standard error of 0.34 . In contrast, the coefficient for the value decile in the high-volatility state is 1.52 , which is more than two standard errors from zero. However, six out of ten book-to-market deciles have insignificant coefficients on the dividend yield. In the low-volatility state the growth decile has a significant coefficient of 0.83 (standard error $=0.28$ ), but the remaining deciles have insignificant coefficients.

Our results so far indicate that value firms are more affected by aggreate economic conditions than growth firms when the conditional volatilities of stock returns are high. To test whether the differential responses between value and growth firms are statistically significant, we report a set of likelihood ratio tests for the existence of two states in the conditional mean equation, as in Perez-Quiros and Timmermann (2000). We condition on the existence of two states in the conditional volatility. (This step is necessary because as pointed out by Hansen (1992), the standard 
likelihood ratio test for multiple states is not defined because the transition probability parameters are not identified under the null of a single state.) The resulting likelihood ratio statistic follows a standard chi-squared distribution. More formally, we test the null hypothesis that the coefficients on the one-month Treasury bill rate, the default spread, the growth rate of money supply, and the dividend yield are equal across states, i.e., $\beta_{k, S_{t}=1}^{i}=\beta_{k, S_{t}=2}^{i}$, for $k=1, \ldots, 4$ and for each testing portfolio $i$. Table 2 shows that the state dependence in the conditional mean equations is indeed statistically significant. The $p$-values for the likelihood ratio tests are equal or smaller than $1 \%$ for seven out of ten deciles, meaning that the null hypothesis is strongly rejected. In particular, the null hypothesis is rejected at the $1 \%$ significance level for the value and growth deciles.

\section{A Joint Model of Expected Value and Growth Returns}

We generalize the previous framework by estimating a bivariate Markov switching model for the excess returns on the value and the growth portfolios. Relative to the univariate framework estimated separately for each portfolio, the bivariate framework offers several advantages. First, the joint framework allows us to impose the condition that the high-volatility state occurs simultaneously for both value and growth portfolios. Doing so allows us to obtain more precise estimates of the underlying state. The joint model also provides a natural framework for modeling the timevarying expected value premium, defined as the difference in expected value and growth returns. Finally, the joint model allows us to formally test the hypothesis that value firms display stronger time-variations in the expected returns than growth firms.

\subsection{Model Specifications}

Let $\mathbf{r}_{t} \equiv\left(r_{t}^{G}, r_{t}^{V}\right)^{\prime}$ be the vector consisting of the excess returns to the growth portfolio, $r_{t}^{G}$, and the excess returns to the value portfolio, $r_{t}^{V}$. We specify the bivariate Markov switching model as:

$$
\mathbf{r}_{t}=\boldsymbol{\beta}_{0, S_{t}}+\boldsymbol{\beta}_{1, S_{t}} T B_{t-1}+\boldsymbol{\beta}_{2, S_{t}} D E F_{t-1}+\boldsymbol{\beta}_{3, S_{t}} \Delta M_{t-2}+\boldsymbol{\beta}_{4, S t} D I V_{t-1}+\boldsymbol{\epsilon}_{t},
$$


in which $\boldsymbol{\beta}_{k, S_{t}} \equiv\left(\begin{array}{c}\beta_{k, S_{t}}^{G} \\ \beta_{k, S_{t}}^{V}\end{array}\right)$ for $k=1,2,3,4$ and $\epsilon_{t} \sim \mathcal{N}\left(0, \Sigma_{S_{t}}\right), S_{t}=\{1,2\}$, is residuals. $\Sigma_{S_{t}}$ is a positive semi-definite $(2 \times 2)$ matrix that contains the variances and covariances of the residuals of the value and growth portfolio excess returns in state $S_{t}$. The diagonal elements of this variancecovariance matrix, $\Sigma_{i i, S_{t}}$, take the similar form as in the univariate model: $\log \left(\Sigma_{i i, S_{t}}\right)=\lambda_{S_{t}}^{i}$. The off-diagonal elements, $\Sigma_{i j, S_{t}}$, assume a state-dependent correlation between the residuals, denoted $\rho_{S_{t}}$, i.e., $\Sigma_{i j, S_{t}}=\rho_{S_{t}}\left(\Sigma_{i i, S_{t}}\right)^{1 / 2}\left(\Sigma_{j j, S_{t}}\right)^{1 / 2}$ for $i \neq j$. We maintain the transition probabilities from the univariate model, but with the same state driving both the value and the growth portfolios.

\subsection{Estimation Results}

Panel C of Figure 1 plots the conditional transition probabilities of being in the high-volatility state at time $t$ conditional on the information set at time $t-1, P\left(S_{t}=1 \mid \Omega_{t-1} ; \boldsymbol{\theta}\right)$. The transitional probabilities of being in the high-volatility state are quite high during the eight post-war recessions. As in the univariate case, high probabilities of being in the high-volatility state are also more frequent than the NBER recessions in the bivariate Markov switching model. Improving on the univariate framework, the bivariate model no longer classifies the second half of the 1990s as recession for growth firms. The reason is that value firms do not have high volatilities during this period. As such, the bivariate model allows cleaner interpretation of the states than the univariate model.

Table 3 presents the estimation results from the bivariate model. Most important, the pattern of differential coefficients on the interest rates and on the default spreads in the conditional mean equations across the value and growth deciles is largely similar to that from the univariate specifications. Moving from growth to value, the coefficient on the Treasury bill rate increases in magnitude from -6.74 (standard error $=2.18$ ) to -10.76 (standard error $=2.25)$ in the highvolatility state. And the coefficient on the default spread increases from 4.60 (standard error $=1.38$ ) for the growth decile to 7.76 (standard error $=1.29$ ) for the value decile in the high-volatility state.

We also present the likelihood ratio tests on the hypothesis that the difference across the two states in the coefficients of the value decile exceeds the difference in the coefficients of the growth 
decile. Formally, for each set of coefficients indexed by $k$, we test the null hypothesis that:

$$
\beta_{k, 1}^{G}-\beta_{k, 2}^{G}=\beta_{k, 1}^{V}-\beta_{k, 2}^{V}
$$

Table 3 shows that the null is strongly rejected at the $5 \%$ significance level for the loadings on the Treasury bill rate and on the default spread. The evidence suggests that the value decile is more sensitive than the growth decile to changes in the Treasury bill rate and in the default spread in the high-volatility state. However, the evidence should be interpreted with caution because the asymmetry tests also reject the null for the loadings on the money growth and on the dividend yield. For these two conditioning variables, the difference across the two states (high-minus-low volatility) in the coefficients of the value decile is negative, while the difference in the coefficients of the growth decile is positive. This evidence contradicts the notion that value stocks covary more with aggregate economic conditions in the high-volatility state than growth stocks.

Imposing the same state across the value and growth deciles changes several results from the univariate specifications. Although the asymmetry test rejects the null hypothesis in equation (17) for the coefficients on the growth in money supply and on the dividend yield, none of the estimates are individually significant. As such, the pattern in the coefficients on the dividend yield across the book-to-market deciles in the univariate specifications in Table 1 does not survive the restriction of a single latent state across the testing portfolios.

\subsection{Time-Variations in the Expected Excess Returns}

Figure 2 plots the expected excess returns for the value portfolio, the growth portfolio, and for the value-minus-growth portfolio. The solid lines use the estimates from the bivariate model, and the dashed lines use the estimates from the univariate model. From the overlay of the NBER recession dates, the expected excess returns of both value and growth deciles tend to increase rapidly during recessions and decline gradually during expansions. Their estimates from the univariate and the bivariate models are largely similar. Panel C reports some discrepancy in the expected value premiums estimated from the univariate and the bivariate models. To the extent that the two estimates 
differ, we rely more on the estimates from the bivariate model to draw our inferences. The reason is that the underlying states are designed to capture shocks to aggregate economic conditions, and that it makes sense to impose the restriction that the states apply to value and growth deciles simultaneously. Estimating the Markov switching model separately for the individual portfolios, while an informative first step, is likely to contaminate the latent states with portfolio-specific shocks.

From Panel C of Figure 2, the expected value premium is positive for 472 out of 648 months, about $73 \%$ of the time. The mean is $0.39 \%$ per month, which is more than 14 standard errors from zero. The expected value premium displays time-variations closely related to the state of the economy: it tends to be small and even negative prior to and during the early phase of recessions, but to increase sharply during later stages of recessions.

As noted, the underlying state in the joint Markov-switching model captures time-varying conditional volatilities, which are correlated with, but not exactly the state of the economy. As such, we also calculate the expected one-year ahead returns for the value and growth deciles, conditional on being in the high-volatility state. Consistent with the evidence in Figure 2, we find that conditional on being in the high-volatility state, expected one-year ahead returns going forward for the value portfolio are substantially higher than those for the growth portfolio: $11.21 \%$ versus $-1.17 \%$ per annum. Conditional on being in the low-volatility state, expected one-year ahead returns for the value portfolio are comparable to those for the growth portfolio: $10.90 \%$ versus $10.26 \%$.

On a related point, we also calculate the average returns of the value and growth deciles in each state. Value outperforms growth in the low-volatility state: $18.92 \%$ versus $15.99 \%$, as well as in the high-volatility state: $12.71 \%$ versus $2.60 \%$. This evidence lends support to the notion that value is unconditionally less risky than growth in the past-war sample (e.g., Lakonishok, Shleifer, and Vishny (1994)). In contrast, the evidence on time-varying expected returns suggests that value is conditionally riskier than growth (e.g., Jagannathan and Wang (1996); Petkova and Zhang (2005)). 


\subsection{Time-Variations in the Conditional Volatilities and Sharpe Ratios}

Time-variations in expected returns can be driven by variations in conditional volatilities, variations in conditional Sharpe ratios, or both. Panel A of Figure 3 plots the conditional volatilities for the value and growth portfolios. The volatilities reflect the switching probabilities, not just the volatilities of returns in a given state. Panel A shows that the conditional volatilities tend to spike upward during most recessions for both value and growth firms. However, the conditional volatilities spike upward much more frequently than the NBER recession dates. Panel B plots the conditional Sharpe ratios for value and growth firms from the bivariate model. The Sharpe ratio dynamics are similar for the value and growth portfolios and both display strong time-variations. The Sharpe ratios tend to increase rapidly during recessions and to decline more gradually in expansions. As such, the time-variations in expected excess returns for value and growth firms in Panel A of Figure 2 are driven by similar variations in both conditional volatilities and conditional Sharpe ratios. The value decile also has mostly higher conditional Sharpe ratios than the growth decile, especially in the early 2000s. Over the entire sample, the mean conditional Sharpe ratio for the value portfolio is 0.66 per annum, which is higher than that of the growth portfolio, 0.38 .

Figure 4 plots conditional volatility and conditional Sharpe ratio for the value-minus-growth portfolio. Because volatility and Sharpe ratio are not additive, we estimate these moments by using the value-minus-growth returns in the univariate Markov switching model. The conditional volatility and the conditional Sharpe ratio of the value-minus-growth portfolio both display strong time-variations. The Sharpe ratio tends to spike upward during recessions, only to decline more gradually in the subsequent expansions. The mean conditional Sharpe ratio is 0.15 per annum.

\subsection{Specification Tests: The Importance of Nonlinearity}

To evaluate the importance of the nonlinearity in the bivariate Markov switching model, we conduct two specification tests, both of which use linear predictive regressions.

In the first specification we regress the realized value premium on the one-period-lagged val- 
ues of the one-month Treasury bill rate, the default spread, and the dividend yield, as well as on the two-period-lagged growth in money supply. The set of instruments is identical to that in the Markov switching model. We identify the fitted component from this regression as the expected value premium from the linear specification without interacted terms. In the second specification we regress the realized value premium on the same set of instruments as well as their interacted terms with the one-period-lagged one-month Treasury bill rate. (We use interacted terms with the one-month Treasury bill rate because it is the instrument used in modeling the state transition probabilities in the Markov switching framework.) We identify the fitted component as the expected value premium from the linear specification with interacted terms.

Figure 6 plots the expected value premiums from the bivariate Markov switching model and from the two linear specifications. Panel A shows that consistent with Chen, Petkova, and Zhang (2008), the linear specification without interacted terms fails to capture the time-variations of the expected value premium. The linear regression completely misses the upward spike in the expected value premium in the early 2000s. Although it captures some time-variations in the expected value premium in the 1974-75 and 1981-82 recessions, the degree of the time-variations is weaker than that from the nonlinear Markov switching model. The volatility of the expected value premium from the linear regression is also lower than that from the bivariate Markov switching model: $1.63 \%$ versus $2.40 \%$ per annum. Finally, using the estimated probability of the high-volatility state as a conditioning variable, we find that the correlation between this probability series and the expected value premium from the nonlinear model is 0.32 . In contrast, the correlation between this probability series and the expected value premium from the linear regression is only 0.19.

Adding interaction terms into the linear predictive regression does not improve its ability to capture time-variations of the expected value premium. From Panel B of Figure 6, the linear specification still misses the upward spike of the expected value premium in the early 2000s, and does not explain fully the time-variations in the 1974-75 and 1981-82 recessions. Although adding interacted terms into the linear specification increases the volatility of the expected value premium 
from $1.63 \%$ to $1.96 \%$ per annum, the correlation between the probability series of the high-volatility state and the expected value premium from the linear specification is reduced from 0.19 to 0.16.

In short, the evidence indicates that the nonlinearity embedded in the Markov switching framework is important for capturing the time-variations of the expected value premium. The nonlinear framework allows more time-variations in the expected value premium when the economy switches back and forth between the states. Such jumps cannot be captured by the linear predictive regressions, with or without the interaction terms, because they rule out such switches by construction.

\subsection{Robustness Tests: Alternative Instruments in Modeling State Transition Probabilities}

In the benchmark estimation we follow Gray (1996) in using the one-month Treasury bill rate as the instrument in modeling the state transition probabilities. We conduct two robustness tests by using two alternative instruments to replace the one-month Treasury bill rate in the transition probabilities specifications in the bivariate Markov switching model. First, we follow Perez-Quiros and Timmermann (2000) in using the year-on-year log-difference in the U.S. Composite Leading Indicator, $\triangle C L I$, as an alternative instrument. The monthly index for the U.S. Composite Leading Indicator is purchased from the Conference Board (BCI individual data series for G0M910: composite index of 10 leading indicators). The index provided by the Conference Board is from March 1960 to December 2007. Second, we use the monthly growth rate of industrial production, defined as $M P_{t} \equiv \log I P_{t}-\log I P_{t-1}$, in which $I P_{t}$ is the index of industrial production in month $t$ from the Federal Reserve Bank of St. Louis. The sample is from January 1954 to December 2007.

Tables 5 and 6 repeat the same tests as in Table 3 by estimating the bivariate Markov switching model for the value and growth portfolio excess returns, but with $\triangle C L I$ and $M P$ as the instrument in modeling state transition probabilities, respectively. The two new tables show that the basic inferences from Table 3 are robust to the specification changes of the state transition probabilities. The expected returns of the value portfolio continue to covary more with the one-month Treasury bill rate and with the default spread in the high-volatility state than the expected returns of the 
growth portfolios. The tests for identical asymmetries (see equation (17)) strongly reject the null hypothesis that value and growth portfolios exhibit the same degree of asymmetry in responding to the one-month Treasury bill rate and the default spread across the two states.

\subsection{Out-of-Sample Forecasts}

Albeit flexible, the Markov switching framework is complex. Because of a large number of parameters being estimated, the in-sample results could severely overstate the degree of predictability in the value premium. To gauge the possibility of overfitting the data in-sample, we study out-of-sample forecasts from the bivariate model.

Specifically, we reestimate the parameters of the model recursively each month to avoid conditioning on information not known prior to that month. We use an expanding window of the data starting from January 1954. We start the out-of-sample forecasts from January 1977 (and end in December 2007) to ensure that we have enough in-sample observations to precisely estimate the nonlinear model. Following Perez-Quiros and Timmermann (2000), we also implement these forecasts in an asset allocation rule to evaluate the economic significance of the stock return predictability.

Figure 5 plots the recursive out-of-sample predicted excess returns to the value and growth portfolios as well as their differences. For comparison, we also overlay the out-of-sample forecasts with in-sample predicted excess returns. The out-of-sample forecasts are highly correlated with the in-sample predictions: their correlations are 0.78 for the value portfolio, 0.40 for the growth portfolio, and 0.39 for the value-minus-growth portfolio. The out-of-sample forecasts and in-sample predictions of excess returns to the value portfolio have similar means, $0.87 \%$ versus $0.95 \%$ per month, and similar volatilities: $1.95 \%$ versus $1.96 \%$. For the excess returns to the growth portfolio, the out-of-sample forecasts have a lower mean than the in-sample predictions: $0.26 \%$ versus $0.49 \%$ per month, but their volatilities are both around $1.40 \%$. The out-of-sample forecasts of the valueminus-growth returns are higher on average than the in-sample predictions, $0.62 \%$ versus $0.46 \%$ per month, but also are more volatile: $2.11 \%$ versus $0.72 \%$ per month. 
As noted, we evaluate the economic significance of the out-of-sample forecasts using a simple asset allocation rule per Perez-Quiros and Timmermann (2000). Under the trading rule, if the excess returns of an equity portfolio are predicted to be positive, we go long in the equity portfolio. Otherwise, we hold the one-month Treasury bill. We examine the risk and returns for such switching portfolios as well as buy-and-hold portfolios (that simply hold the equity portfolio in question).

Table 4 shows that the economic significance of out-of-sample predictability is close to nonexistent. In the full sample, the switching portfolio based on the growth decile only slightly outperforms the buy-and-hold portfolio in terms of average returns: $11.28 \%$ versus $11.16 \%$. For the value decile, the switching portfolio even underperforms the buy-and-hold portfolio in average returns: $16.88 \%$ versus $17.45 \%$. Although the switching portfolios deliver slightly higher Sharpe ratios than the respective buy-and-hold portfolios, the evidence cannot be interpreted as out-of-sample predictability. The reason is that the switching portfolios have similar average returns but lower volatilities than the buy-and-hold portfolios. However, this result is mechanical because the switching portfolios only use information on the conditional means, but not on the conditional volatilities.

From Panel B, the value of market timing varies across the states. In the NBER recessions, the average returns of the switching portfolios are substantially higher than those of the respective buy-and-hold portfolios. In particular, the buy-and-hold portfolio based on the growth decile has a mean return of $-1.5 \%$ per annum, while the switching portfolio based on the growth decile has a mean return of $12.27 \%$. Building on the value decile yields similar results: the buy-and-hold portfolio's mean return is $2.23 \%$, while the switching portfolio's mean return is $15.26 \%$. Because the NBER recessions are ex post, we also report the results in the high-volatility state from recursively estimating the bivariate model. Although the patterns are less dramatic than those from the NBER recessions, the results suggest similar inferences. However, Panel C shows that the switching portfolios underperform the buy-and-hold portfolios in terms of average returns both in the NBER expansions as well as in the low-volatility states identified by the bivariate model. 


\section{Summary and Interpretation}

Using the two-state Markov switching framework of Perez-Quiros and Timmermann (2000), we document that the expected value premium displays strong time-variations. In the high-volatility state, the expected excess returns of value stocks are more sensitive to aggregate economic conditions than the expected excess returns of growth stocks. In contrast, in the low-volatility state the expected excess returns of both value and growth stocks have mostly insignificant loadings on aggregate conditioning variables. Because of these asymmetries across the state of the economy, the expected value premium tends to spike upward rapidly during high-volatility periods (including recessions), only to decline more gradually in the subsequent low-volatility periods (including expansions). Our evidence lends support to the conditional asset pricing literature (e.g, Jagannathan and Wang (1996); Ferson and Harvey (1999); Lettau and Ludvigson (2001)).

Why should the expected returns of value firms covary more with bad states of the world than the expected returns of growth firms? Equivalently, why should the expected value premium display time-variations? Investment-based asset pricing theories have provided some clues. Carlson, Fisher, and Giammarino (2004) argue that when demand for the product of the firms in the economy decreases, equity values fall relative to book values and revenues fall relative to the average level. For value firms, equity values fall more relative to book values and revenues fall more relative to the average, meaning that value firms have higher operating leverage than growth firms. This operating leverage mechanism causes value firms to be more affected by negative aggregate shocks than growth firms. As such, the risk and expected returns of value firms increase more than the risk and expected returns of growth firms in recessions. Zhang (2005) argues that because of costly reversibility, value firms are less flexible than growth firms in scaling down to mitigate the impact of negative shocks. Costly reversibility means that firms face higher costs in cutting than in expanding the scale of productive assets. Because the assets of value firms are less profitable than growth firms, value firms want to disinvest more in recessions. Because disinvesting is more costly than investing, the fundamentals of value firms are more adversely affected by worsening economic 
conditions than the fundamentals of growth firms. Finally, Livdan, Sapriza, and Zhang (2009) argue that more leveraged firms are burdened with more debt and must pay more interests and retire a higher amount of the existing debt before financing new investments. As such, more leveraged firms are more likely to face binding collateral constraints, are less flexible in using investment to smooth dividends and riskier, and should earn higher expected returns than less leveraged firms. 


\section{References}

Ang, Andrew and Geert Bekaert, 2002a, International asset allocation with regime shifts, Review of Financial Studies 15, 1137-1187.

Ang, Andrew and Geert Bekaert, 2002b, Regime switches in interest rates, Journal of Business and Economic Statistics 20, 163-182.

Bekaert, Geert and Campbell R. Harvey, 1995, Time-varying world market integration, Journal of Finance 50, 403-444.

Bernanke, Ben S., 1990, On the predictive power of interest rates and interest rate spreads, New England Economic Review 51-68.

Bernanke, Ben S. and Mark Gertler, 1989, Agency costs, net worth, and business fluctuations, American Economic Review 79, 14-31.

Berk, Jonathan B, Richard C. Green, and Vasant Naik, 1999, Optimal investment, growth options, and security returns, Journal of Finance 54, 1153-1607.

Carlson, Murray, Adlai Fisher, and Ron Giammarino, 2004, Corporate investment and asset price dynamics: Implications for the cross section of returns, Journal of Finance 59, 2577-2603.

Campbell, John Y., 1987, Stock returns and the term structure, Journal of Financial Economics 18, 373-399.

Campbell, John Y. and Robert J. Shiller, 1988, The dividend-price ratio and expectations of future dividends and discount factors, Review of Financial Studies 1, 195-228.

Chen, Long, Ralitsa Petkova, and Lu Zhang, 2008, The expected value premium, Journal of Financial Economics 87, 269-280.

Cochrane, John H., 1991, Production-based asset pricing and the link between stock returns and economic fluctuations, Journal of Finance 46, 209-237.

Cohen, Randolph B., Christopher Polk, and Tuomo Vuolteenaho, 2003, The value spread, Journal of Finance 58, 609-641.

Fama, Eugene F., 1981, Stock returns, real activity, inflation, and money, American Economic Review 71, 545-565.

Fama, Eugene F., and Kenneth R. French, 1989, Business conditions and expected returns on stocks and bonds, Journal of Financial Economics 25, 23-49.

Fama, Eugene F. and G. William Schwert, 1977, Asset returns and inflation, Journal of Financial Economics 5, 115-146.

Ferson, Wayne E. and Campbell R. Harvey, 1999, Conditioning variables and the cross section of stock returns, Journal of Finance 54, 1325-1360.

Filardo, Andrew J., 1994, Business cycle phases and their transitional dynamics, Journal of Business and Economic Statistics 12, 299-308. 
Gertler, Mark and Simon Gilchrist, 1994, Monetary policy, business cycles, and the behavior of small manufacturing firms, Quarterly Journal of Economics 109, 309-340.

Gray, Stephen F., 1996, Modeling the conditional distribution of interest rates as a regime switching process, Journal of Financial Economics 42, 27-62.

Guidolin, Massimo and Allan Timmermann, 2006, An econometric model of nonlinear dynamics in the joint distribution of stock and bond returns, Journal of Applied Econometrics 21, 1-22.

Guidolin, Massimo and Allan Timmermann, 2008a, International asset allocation under regime switching, skewness, and kurtosis, Review of Financial Studies 21, 889-935.

Guidolin, Massimo and Allan Timmermann, 2008b, Size and value anomalies under regime shifts, Journal of Financial Econometrics 6, 1-48.

Hamilton, James D., 1989, A new approach to the economic analysis of non-stationary time series and the business cycle, Econometrica 57, 357-384.

Hansen, Bruce E., 1992, The likelihood ratio test under nonstandard conditions: Testing the Markov switching model of GNP, Journal of Applied Econometrics 7, S61-S82.

Jagannathan, Ravi and Zhengyu Wang, 1996, The conditional CAPM and the cross-section of expected returns, Journal of Finance 51, 3-53.

Kiyotaki, Nobuhiro and John Moore, 1997, Credit cycles, Journal of Political Economy 105, 211248.

Lakonishok, Josef, Andrei Shleifer, and Robert W. Vishny, 1994, Contrarian investment, extrapolation, and risk, Journal of Finance 49, 1541-1578.

Lettau, Martin, and Sydney Ludvigson, 2001, Resurrecting the (C)CAPM: A cross-sectional test when risk premia are time-varying, Journal of Political Economy 109, 1238-1287.

Lewellen, Jonathan, and Stefan Nagel, 2006, The conditional CAPM does not explain asset-pricing anomalies, Journal of Financial Economics 82, 289-314.

Livdan, Dmitry, Horacio Sapriza, and Lu Zhang, 2009, Financially constrained stock returns, Journal of Finance 64, 1827-1862.

Petkova, Ralitsa and Lu Zhang, 2005, Is value riskier than growth? Journal of Financial Economics 78, 187-202.

Perez-Quiros, Gabriel and Allan Timmermann, 2000, Firm size and cyclical variations in stock returns, Journal of Finance 55, 1229-1262.

Pontiff, Jeffrey and Lawrence Schall, 1999, Book to market as a predictor of market returns, Journal of Financial Economics 49, 141-160.

Schwert, G. William, 1989, Why does stock market volatility change over time? Journal of Finance $29,1115-1153$.

Zhang, Lu, 2005, The value premium, Journal of Finance 60, 67-103. 
Table 1 : Parameter Estimates for the Univariate Markov Switching Model of Excess Returns on Decile Portfolios Formed on Book-to-Market Equity (January 1954 to December 2007)

For each book-to-market decile $i$, we estimate the following two-state Markov switching model:

$$
\begin{aligned}
r_{t}^{i} & =\beta_{0, S_{t}}^{i}+\beta_{1, S_{t}}^{i} T B_{t-1}+\beta_{2, S_{t}}^{i} D E F_{t-1}+\beta_{3, S_{t}}^{i} \Delta M_{t-2}+\beta_{4, S_{t}}^{i} D I V_{t-1}+\epsilon_{t}^{i} \\
\epsilon_{t}^{i} & \sim N\left(0, \sigma_{i, S_{t}}^{2}\right), \quad S_{t}^{i}=\{1,2\} \\
p_{t}^{i} & =P\left(S_{t}^{i}=1 \mid S_{t-1}^{i}=1\right)=\Phi\left(\pi_{0}^{i}+\pi_{1}^{i} T B_{t-1}\right) ; \quad 1-p_{t}^{i}=P\left(S_{t}^{i}=2 \mid S_{t-1}^{i}=1\right) \\
q_{t}^{i} & =P\left(S_{t}^{i}=2 \mid S_{t-1}^{i}=2\right)=\Phi\left(\pi_{0}^{i}+\pi_{2}^{i} T B_{t-1}\right) ; \quad 1-q_{t}^{i}=P\left(S_{t}^{i}=1 \mid S_{t-1}^{i}=2\right)
\end{aligned}
$$

in which $r_{t}^{i}$ is the monthly excess return for a given decile portfolio and $S_{t}^{i}$ is the regime indicator.

\begin{tabular}{|c|c|c|c|c|c|}
\hline & Growth & Decile 2 & Decile 3 & Decile 4 & Decile 5 \\
\hline Constant, state 1 & $-0.027(0.01)$ & $-0.017(0.01)$ & $-0.015(0.01)$ & $-0.043(0.02)$ & $-0.088(0.02)$ \\
\hline Constant, state 2 & $-0.019(0.01)$ & $-0.009(0.01)$ & $-0.005(0.02)$ & $0.004(0.01)$ & $0.016(0.01)$ \\
\hline$T B$, state 1 & $-5.681(1.54)$ & $-5.624(1.63)$ & $-6.439(1.21)$ & $-6.980(2.53)$ & $-7.185(3.16)$ \\
\hline$T B$, state 2 & $-1.454(1.51)$ & $-1.406(1.91)$ & $-1.640(1.95)$ & $-1.917(1.17)$ & $-3.197(1.12)$ \\
\hline$D E F$, state 1 & $4.019(0.88)$ & $3.848(0.83)$ & $3.136(0.69)$ & $5.617(1.28)$ & $5.136(1.79)$ \\
\hline$D E F$, state 2 & $1.769(0.96)$ & $1.763(1.07)$ & $1.162(1.12)$ & $1.328(0.73)$ & $0.450(0.65)$ \\
\hline$\Delta M$, state 1 & $0.077(0.06)$ & $0.045(0.06)$ & $0.019(0.04)$ & $0.063(0.11)$ & $0.124(0.10)$ \\
\hline$\Delta M$, state 2 & $-0.049(0.06)$ & $-0.045(0.06)$ & $-0.031(0.05)$ & $-0.011(0.04)$ & $-0.029(0.03)$ \\
\hline$D I V$, state 1 & $0.220(0.34)$ & $0.122(0.37)$ & $0.486(0.26)$ & $0.271(0.65)$ & $1.795(0.75)$ \\
\hline$D I V$, state 2 & $0.832(0.28)$ & $0.397(0.26)$ & $0.473(0.28)$ & $0.055(0.20)$ & $0.112(0.18)$ \\
\hline \multicolumn{6}{|c|}{ Transition probability parameters } \\
\hline Constant & $1.568(0.40)$ & $1.647(0.54)$ & $1.994(0.57)$ & $1.775(0.47)$ & $2.178(0.44)$ \\
\hline$T B$, state 1 & $0.828(0.92)$ & $0.889(1.31)$ & $0.783(1.71)$ & $-0.047(0.79)$ & $-1.684(0.83)$ \\
\hline$T B$, state 2 & $0.131(1.03)$ & $0.155(1.48)$ & $-0.819(1.92)$ & $0.128(0.88)$ & $-1.124(0.82)$ \\
\hline \multicolumn{6}{|l|}{ Standard deviation } \\
\hline$\sigma$, state 1 & $0.059(0.00)$ & $0.053(0.00)$ & $0.050(0.00)$ & $0.059(0.00)$ & $0.057(0.00)$ \\
\hline$\sigma$, state 2 & $0.028(0.00)$ & $0.030(0.00)$ & $0.024(0.00)$ & $0.033(0.00)$ & $0.032(0.00)$ \\
\hline \multirow[t]{2}{*}{ Log likelihood value } & 1056 & 1112 & 1127 & 1133 & 1170 \\
\hline & Decile 6 & Decile 7 & Decile 8 & Decile 9 & Value \\
\hline Constant, state 1 & $-0.060(0.03)$ & $-0.088(0.02)$ & $-0.091(0.03)$ & $-0.070(0.03)$ & $-0.082(0.03)$ \\
\hline Constant, state 2 & $0.009(0.01)$ & $0.021(0.01)$ & $0.011(0.01)$ & $0.010(0.01)$ & $0.010(0.01)$ \\
\hline$T B$, state 1 & $-7.725(3.92)$ & $-8.432(2.80)$ & $-8.810(3.12)$ & $-9.350(3.24)$ & $-11.667(3.28)$ \\
\hline$T B$, state 2 & $-2.309(1.05)$ & $-1.983(1.08)$ & $-2.447(1.02)$ & $-1.389(1.05)$ & $-1.339(1.12)$ \\
\hline$D E F$, state 1 & $5.951(1.93)$ & $6.180(1.48)$ & $6.402(1.84)$ & $6.853(1.92)$ & $7.309(1.79)$ \\
\hline$D E F$, state 2 & $0.392(0.63)$ & $-0.077(0.65)$ & $0.526(0.57)$ & $0.335(0.57)$ & $0.382(0.62)$ \\
\hline$\Delta M$, state 1 & $0.095(0.17)$ & $0.135(0.10)$ & $0.052(0.11)$ & $0.066(0.09)$ & $0.182(0.12)$ \\
\hline$\Delta M$, state 2 & $0.000(0.03)$ & $-0.069(0.03)$ & $-0.01(0.03)$ & $-0.019(0.03)$ & $0.019(0.03)$ \\
\hline$D I V$, state 1 & $0.697(0.89)$ & $1.605(0.63)$ & $1.839(0.64)$ & $1.190(0.67)$ & $1.523(0.75)$ \\
\hline$D I V$, state 2 & $0.181(0.19)$ & $0.085(0.19)$ & $0.223(0.20)$ & $0.196(0.19)$ & $0.137(0.22)$ \\
\hline \multicolumn{6}{|c|}{ Transition probability parameters } \\
\hline Constant & $1.704(0.44)$ & $1.436(0.22)$ & $1.354(0.45)$ & $1.278(0.40)$ & $1.409(0.36)$ \\
\hline$T B$, state 1 & $-0.754(0.82)$ & $-0.869(0.41)$ & $-0.806(0.83)$ & $-0.573(0.80)$ & $-0.056(0.71)$ \\
\hline$T B$, state 2 & $0.125(0.73)$ & $-0.008(0.27)$ & $0.439(0.75)$ & $0.350(0.76)$ & $0.752(0.75)$ \\
\hline \multicolumn{6}{|l|}{ Standard deviation } \\
\hline$\sigma$, state 1 & $0.059(0.00)$ & $0.054(0.00)$ & $0.058(0.00)$ & $0.062(0.00)$ & $0.072(0.00)$ \\
\hline$\sigma$, state 2 & $0.033(0.00)$ & $0.031(0.00)$ & $0.033(0.00)$ & $0.031(0.00)$ & $0.037(0.00)$ \\
\hline Log likelihood value & 1165 & 1160 & 1150 & 1121 & 1035 \\
\hline
\end{tabular}
$T B$ is the one-month Treasury bill rate, $D E F$ is the yield spread between Baa- and Aaa-rated corporate bonds, $\triangle M$ is the annual rate of growth of the monetary base, and $D I V$ is the dividend yield of the CRSP value-weighted portfolio. Standard errors are reported in parentheses. 


\section{Table 2 : Tests for Identical Slope Coefficients Across States in the Markov Switching Model (January 1954 to December 2007)}

For each book-to-market decile, we estimate the following two-state Markov switching model:

$$
\begin{aligned}
& r_{t}^{i}=\beta_{0, S_{t}}^{i}+\beta_{1, S_{t}}^{i} T B_{t-1}+\beta_{2, S_{t}}^{i} D E F_{t-1}+\beta_{3, S_{t}}^{i} \Delta M_{t-2}+\beta_{4, S_{t}}^{i} D I V_{t-1}+\epsilon_{t}^{i} \\
& \epsilon_{t}^{i} \sim N\left(0, \sigma_{i, S_{t}}^{2}\right), \quad S_{t}^{i}=\{1,2\} \\
& p_{t}^{i}=P\left(S_{t}^{i}=1 \mid S_{t-1}^{i}=1\right)=\Phi\left(\pi_{0}^{i}+\pi_{1}^{i} T B_{t-1}\right) ; \quad 1-p_{t}^{i}=P\left(S_{t}^{i}=2 \mid S_{t-1}^{i}=1\right) \\
& q_{t}^{i}=P\left(S_{t}^{i}=2 \mid S_{t-1}^{i}=2\right)=\Phi\left(\pi_{0}^{i}+\pi_{2}^{i} T B_{t-1}\right) ; \quad 1-q_{t}^{i}=P\left(S_{t}^{i}=1 \mid S_{t-1}^{i}=2\right)
\end{aligned}
$$

in which $r_{t}^{i}$ is the monthly excess return for a given decile portfolio and $S_{t}^{i}$ is the regime indicator. $T B$ is the one-month Treasury bill rate, $D E F$ is the yield spread between Baa- and Aaa-rated corporate bonds, $\triangle M$ is the annual growth rate of the money supply, and $D I V$ is the dividend yield of the CRSP value-weighted portfolio. We conduct likelihood ratio tests on the null hypothesis that the coefficients

\begin{tabular}{|c|c|c|c|c|c|}
\hline & Growth & Decile 2 & Decile 3 & Decile 4 & Decile 5 \\
\hline Unrestricted log likelihood value & 1056 & 1112 & 1127 & 1133 & 1170 \\
\hline Restricted log likelihood with $\beta_{k, S_{t}=1}=\beta_{k, S_{t}=2}, k=\{1,2,3,4\}$ & 1047 & 1105 & 1120 & 1130 & 1162 \\
\hline \multirow[t]{2}{*}{$p$-value } & 0.00 & 0.01 & 0.01 & 0.33 & 0.00 \\
\hline & Decile 6 & Decile 7 & Decile 8 & Decile 9 & Value \\
\hline Unrestricted log likelihood value & 1165 & 1160 & 1150 & 1121 & 1034 \\
\hline Restricted log likelihood with $\beta_{k, S_{t}=1}=\beta_{k, S_{t}=2}, k=\{1,2,3,4\}$ & 1162 & 1138 & 1148 & 1102 & 1014 \\
\hline$p$-value & 0.14 & 0.00 & 0.41 & 0.00 & 0.00 \\
\hline
\end{tabular}
are equal across states, i.e., $\beta_{k, S_{t}=1}^{i}=\beta_{k, S_{t}=2}^{i}, k=\{1,2,3,4\}$, for each book-to-market decile $i$. The $p$-value is the probability that the null hypothesis is not rejected. When testing the null hypothesis, we condition on the existence of two states in the conditional volatility. 
Table 3 : The Joint Markov Switching Model for Excess Returns to the Value Decile and on the Growth Decile (January 1954 to December 2007)

We estimate the following model for excess returns to value and growth deciles:

$$
\begin{aligned}
\mathbf{r}_{t} & =\boldsymbol{\beta}_{0, S_{t}}+\boldsymbol{\beta}_{1, S_{t}} T B_{t-1}+\boldsymbol{\beta}_{2, S_{t}} D E F_{t-1}+\boldsymbol{\beta}_{3, S_{t}} \Delta M_{t-2}+\boldsymbol{\beta}_{4, S_{t}} D I V_{t-1}+\boldsymbol{\epsilon}_{t} \\
\boldsymbol{\epsilon}_{t} & \sim N\left(0, \Sigma_{S_{t}}\right), \quad S_{t}=\{1,2\} \\
\log \left(\Sigma_{i i, S_{t}}\right) & =\lambda_{S_{t}}^{i} ; \quad \Sigma_{i j, S_{t}}=\rho_{S_{t}}\left(\Sigma_{i i, S_{t}}\right)^{1 / 2}\left(\Sigma_{j j, S_{t}}\right)^{1 / 2}, \quad i \neq j \\
p_{t} & =P\left(S_{t}=1 \mid S_{t-1}=1\right)=\Phi\left(\pi_{0}+\pi_{1} T B_{t-1}\right) ; \quad 1-p_{t}=P\left(S_{t}=2 \mid S_{t-1}=1\right) \\
q_{t} & =P\left(S_{t}=2 \mid S_{t-1}=2\right)=\Phi\left(\pi_{0}+\pi_{2} T B_{t-1}\right) ; \quad 1-q_{t}=P\left(S_{t}=1 \mid S_{t-1}=2\right)
\end{aligned}
$$

in which $\mathbf{r}_{t}=\left(r_{t}^{G}, r_{t}^{V}\right)^{\prime}$ is the $(2 \times 1)$ vector that contains the monthly excess returns on the growth and value portfolios, $r_{t}^{G}$ and $r_{t}^{V}$, respectively. $\boldsymbol{\beta}_{k, S_{t}}, k=0,1,2,3,4$, is a $(2 \times 1)$ vector with elements $\boldsymbol{\beta}_{k, S_{t}}=\left(\beta_{k, S_{t}}^{G}, \beta_{k, S_{t}}^{V}\right)^{\prime} . \boldsymbol{\epsilon}_{t} \sim \mathcal{N}\left(0, \Sigma_{S_{t}}\right)$ is a vector of residuals. $\Sigma_{S_{t}}$ is a positive semidefinite $(2 \times 2)$ matrix containing the variances and covariances of the residuals of the value and growth portfolio excess returns in state $S_{t}$. The diagonal elements of this variance-covariance matrix, $\Sigma_{i i, S_{t}}$, take the similar form as in the univariate model: $\log \left(\Sigma_{i i, S_{t}}\right)=\lambda_{S_{t}}^{i}$. The off-diagonal elements, $\Sigma_{i j, S_{t}}$, assume a state-dependent correlation between the residuals, denoted $\rho_{S_{t}}$, i.e., $\Sigma_{i j, S_{t}}=\rho_{S_{t}}\left(\Sigma_{i i, S_{t}}\right)^{1 / 2}\left(\Sigma_{j j, S_{t}}\right)^{1 / 2}$ for $i \neq j$. TB is the one-month Treasury bill rate, $D E F$ is the yield spread between Baa- and Aaa-rated corporate bonds, $\Delta M$ is the annual rate of growth of the monetary base, and $D I V$ is the dividend yield of the value-weighted market portfolio. $\Phi$ is

\begin{tabular}{|c|c|c|c|c|}
\hline & Growth & Value & \multicolumn{2}{|c|}{ Tests for identical asymmetries } \\
\hline & & & \multicolumn{2}{|c|}{ Constant: $\beta_{0,1}^{G}-\beta_{0,2}^{G}=\beta_{0,1}^{V}-\beta_{0,2}^{V}$} \\
\hline Constant, state 1 & $-0.043(0.02)$ & $-0.047(0.02)$ & Log likelihood value & 2243 \\
\hline Constant, state 2 & $-0.004(0.01)$ & $-0.003(0.01)$ & $p$-value & $(0.30)$ \\
\hline \multicolumn{5}{|c|}{$T B: \beta_{1,1}^{G}-\beta_{1,2}^{G}=\beta_{1,1}^{V}-\beta_{1,2}^{V}$} \\
\hline$T B$, state 1 & $-6.741(2.18)$ & $-10.758(2.25)$ & Log likelihood value & 2241 \\
\hline$T B$, state 2 & $-1.725(1.47)$ & $-2.965(1.41)$ & $p$-value & $(0.02)$ \\
\hline \multicolumn{5}{|c|}{$D E F: \beta_{2,1}^{G}-\beta_{2,2}^{G}=\beta_{2,1}^{V}-\beta_{2,2}^{V}$} \\
\hline$D E F$, state 1 & $4.599(1.38)$ & $7.761(1.29)$ & Log likelihood value & 2240 \\
\hline$D E F$, state 2 & $1.057(0.72)$ & $1.285(0.77)$ & $p$-value & $(0.01)$ \\
\hline \multicolumn{5}{|c|}{$\Delta M: \beta_{3,1}^{G}-\beta_{3,2}^{G}=\beta_{3,1}^{V}-\beta_{3,2}^{V}$} \\
\hline$\Delta M$, state 1 & $0.093(0.08)$ & $0.081(0.08)$ & Log likelihood value & 2240 \\
\hline$\Delta M$, state 2 & $0.024(0.06)$ & $0.084(0.06)$ & $p$-value & $(0.01)$ \\
\hline \multicolumn{5}{|c|}{$D I V: \beta_{4,1}^{G}-\beta_{4,2}^{G}=\beta_{4,1}^{V}-\beta_{4,2}^{V}$} \\
\hline$D I V$, state 1 & $0.448(0.49)$ & $0.387(0.25)$ & Log likelihood value & 2241 \\
\hline$D I V$, state 2 & $0.420(0.47)$ & $0.430(0.25)$ & $p$-value & $(0.02)$ \\
\hline \multicolumn{5}{|c|}{ Standard deviation parameters } \\
\hline$\sigma$, state 1 & $0.064(0.00)$ & $0.070(0.00)$ & & \\
\hline$\sigma$, state 2 & $0.037(0.00)$ & $0.037(0.00)$ & & \\
\hline
\end{tabular}
the cumulative density function of a standard normal variable. Standard errors are in parentheses to the right of the estimates. The $p$-value from the likelihood ratio test is the probability of the restriction that the asymmetry between the value and growth portfolios is identical against the alternative that the asymmetry is larger for the value portfolio.

Correlation parameters

$\rho$, state 1

$0.638 \quad(0.05)$

$\rho$, state 2

$0.665 \quad(0.04)$

Transition probability parameters

Constant

$T B$, state 1

$0.250 \quad(0.58)$

$T B$, state 2

$0.375 \quad(0.68)$

$T B: \pi_{1}=\pi_{2}$

Log likelihood value

$p$-value

Unconstrained log likelihood

2244 
Table 4 : Out-of-Sample Trading Results (January 1977 to December 2007)

Trading results are based on positions in the book-to-market portfolios and in the one-month Treasury bill. The buy-and-hold strategy reinvests all funds in a given book-to-market decile, while the switching portfolios take a long position in the book-to-market portfolio if the recursively predicted excess return is positive, otherwise the position switches into the one-month Treasury bill. Average returns and return volatilities are annualized.

\begin{tabular}{|c|c|c|c|c|c|}
\hline \multirow{6}{*}{$\begin{array}{l}\text { Average return } \\
\text { Return volatility } \\
\text { Sharpe ratio }\end{array}$} & \multicolumn{3}{|c|}{ Growth } & \multicolumn{2}{|c|}{ Value } \\
\hline & $\begin{array}{r}\text { Treasury } \\
\text { bill } \\
\end{array}$ & Buy-and-hold & $\begin{array}{r}\text { Switching } \\
\text { portfolio }\end{array}$ & buy-and-hold & $\begin{array}{r}\text { Switching } \\
\text { portfolio }\end{array}$ \\
\hline & \multicolumn{5}{|c|}{ Panel A: The full sample } \\
\hline & 5.84 & 11.16 & 11.28 & 17.45 & 16.88 \\
\hline & 0.88 & 17.94 & 13.21 & 16.87 & 13.70 \\
\hline & & 0.09 & 0.12 & 0.20 & 0.23 \\
\hline & \multicolumn{5}{|c|}{ Panel B: Bad states } \\
\hline & \multicolumn{5}{|c|}{ NBER recessions } \\
\hline Average return & 8.88 & -1.50 & 12.27 & 2.23 & 15.26 \\
\hline Return volatility & 1.14 & 23.05 & 14.58 & 23.05 & 16.65 \\
\hline \multirow[t]{2}{*}{ Sharpe ratio } & & -0.13 & 0.07 & -0.08 & 0.11 \\
\hline & \multicolumn{5}{|c|}{ High-volatility states } \\
\hline Average return & 8.57 & 11.81 & 20.02 & 10.64 & 21.17 \\
\hline Return volatility & 1.13 & 24.21 & 16.45 & 23.87 & 17.63 \\
\hline \multirow[t]{3}{*}{ Sharpe ratio } & & 0.04 & 0.20 & 0.03 & 0.21 \\
\hline & \multicolumn{5}{|c|}{ Panel C: Good states } \\
\hline & \multicolumn{5}{|c|}{ NBER expansions } \\
\hline Average return & 5.49 & 12.65 & 11.16 & 19.23 & 17.07 \\
\hline Return volatility & 0.78 & 17.24 & 13.07 & 15.96 & 13.34 \\
\hline \multirow[t]{2}{*}{ Sharpe ratio } & & 0.12 & 0.13 & 0.25 & 0.25 \\
\hline & \multicolumn{5}{|c|}{ Low-volatility states } \\
\hline Average return & 5.52 & 11.09 & 10.26 & 18.25 & 16.38 \\
\hline Return volatility & 0.79 & 17.11 & 12.78 & 15.89 & 13.19 \\
\hline Sharpe ratio & & 0.09 & 0.11 & 0.23 & 0.24 \\
\hline
\end{tabular}


Table 5 : The Joint Markov Switching Model for Excess Returns to the Value Decile and on the Growth Decile (March 1960 to December 2007), $\triangle C L I$ As an Alternative Instrument in Modeling State Transition Probabilities

We estimate the following model for excess returns to value and growth deciles:

$$
\begin{aligned}
\mathbf{r}_{t} & =\boldsymbol{\beta}_{0, S_{t}}+\boldsymbol{\beta}_{1, S_{t}} T B_{t-1}+\boldsymbol{\beta}_{2, S_{t}} D E F_{t-1}+\boldsymbol{\beta}_{3, S_{t}} \Delta M_{t-2}+\boldsymbol{\beta}_{4, S_{t}} D I V_{t-1}+\boldsymbol{\epsilon}_{t} \\
\boldsymbol{\epsilon}_{t} & \sim N\left(0, \Sigma_{S_{t}}\right), \quad S_{t}=\{1,2\} \\
\log \left(\Sigma_{i i, S_{t}}\right) & =\lambda_{S_{t}}^{i} ; \quad \Sigma_{i j, S_{t}}=\rho_{S_{t}}\left(\Sigma_{i i, S_{t}}\right)^{1 / 2}\left(\Sigma_{j j, S_{t}}\right)^{1 / 2}, \quad i \neq j \\
p_{t} & =P\left(S_{t}=1 \mid S_{t-1}=1\right)=\Phi\left(\pi_{0}+\pi_{1} \triangle C L I_{t-1}\right) ; \quad 1-p_{t}=P\left(S_{t}=2 \mid S_{t-1}=1\right) \\
q_{t} & =P\left(S_{t}=2 \mid S_{t-1}=2\right)=\Phi\left(\pi_{0}+\pi_{2} \triangle C L I_{t-1}\right) ; \quad 1-q_{t}=P\left(S_{t}=1 \mid S_{t-1}=2\right)
\end{aligned}
$$

in which $\mathbf{r}_{t}=\left(r_{t}^{G}, r_{t}^{V}\right)^{\prime}$ is the $(2 \times 1)$ vector that contains the monthly excess returns on the growth and value portfolios, $r_{t}^{G}$ and $r_{t}^{V}$, respectively. $\boldsymbol{\beta}_{k, S_{t}}, k=0,1,2,3,4$, is a $(2 \times 1)$ vector with elements $\boldsymbol{\beta}_{k, S_{t}}=\left(\beta_{k, S_{t}}^{G}, \beta_{k, S_{t}}^{V}\right)^{\prime} . \boldsymbol{\epsilon}_{t} \sim \mathcal{N}\left(0, \Sigma_{S_{t}}\right)$ is a vector of residuals. $\Sigma_{S_{t}}$ is a positive semidefinite $(2 \times 2)$ matrix containing the variances and covariances of the residuals of the value and growth portfolio excess returns in state $S_{t}$. The diagonal elements of this variance-covariance matrix, $\Sigma_{i i, S_{t}}$, take the similar form as in the univariate model: $\log \left(\Sigma_{i i, S_{t}}\right)=\lambda_{S_{t}}^{i}$. The off-diagonal elements, $\Sigma_{i j, S_{t}}$, assume a state-dependent correlation between the residuals, denoted $\rho_{S_{t}}$, i.e., $\Sigma_{i j, S_{t}}=\rho_{S_{t}}\left(\Sigma_{i i, S_{t}}\right)^{1 / 2}\left(\Sigma_{j j, S_{t}}\right)^{1 / 2}$ for $i \neq j$. TB is the one-month Treasury bill rate, $D E F$ is the yield spread between Baa- and Aaa-rated corporate bonds, $\Delta M$ is the annual rate of growth of the monetary base, and $D I V$ is the dividend yield of the value-weighted market portfolio. $\triangle C L I$ is the year-on-year log-difference in the Composite Leading Indicator from the Conference Board. $\Phi$ is the cumulative density function of a standard normal variable. Standard errors are in parentheses to the right of the estimates. The $p$-value from the likelihood ratio test is the probability of the restriction that the asymmetry between the value and growth portfolios is identical against the alternative that the asymmetry is larger for the value portfolio.

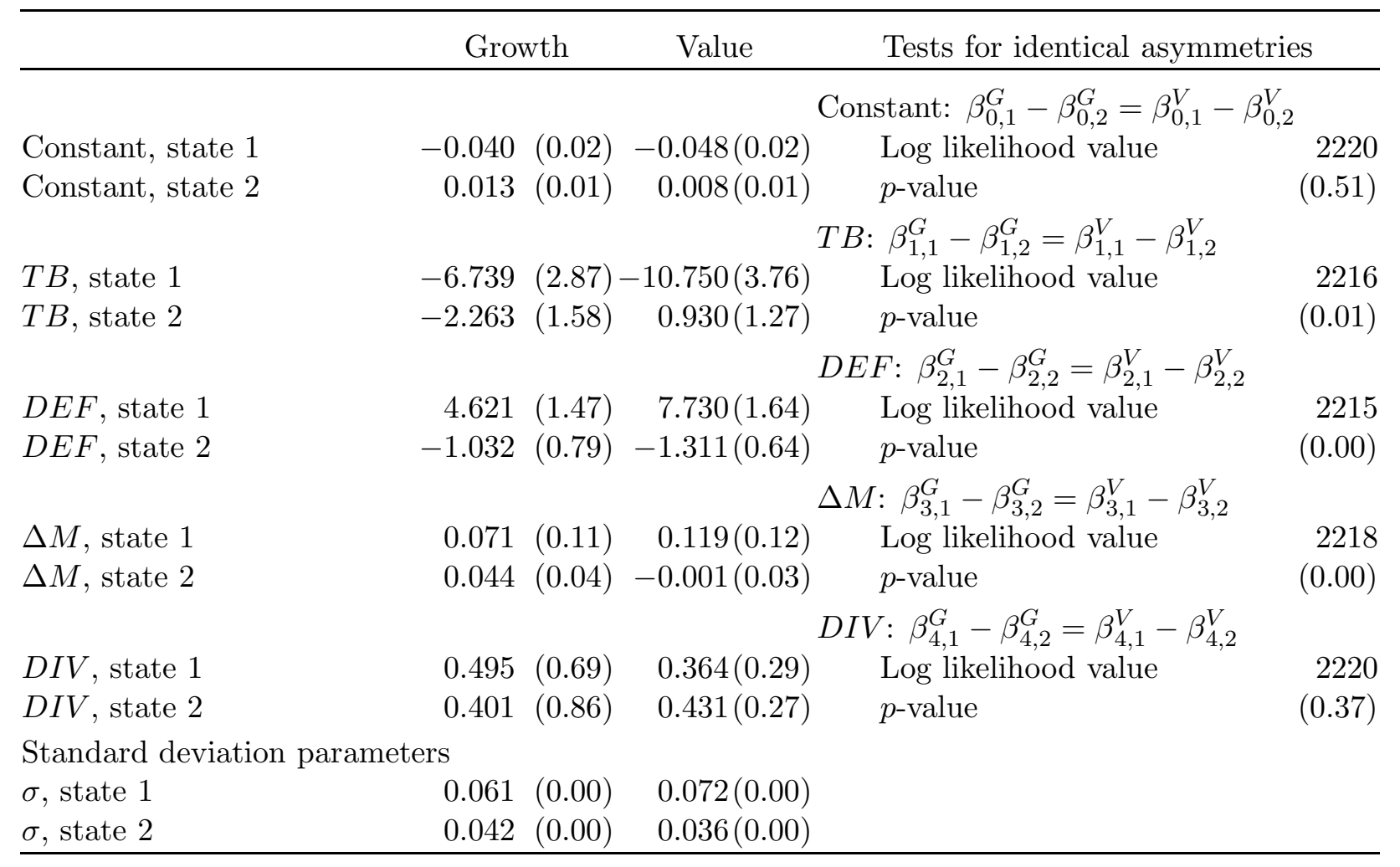

Parameters common to both deciles

Correlation parameters

$\rho$, state 1

$0.643 \quad(0.05)$

$\rho$, state 2

$0.609 \quad(0.04)$

Transition probability parameters

Constant

$\triangle C L I$, state 1

TB: $\pi_{1}=\pi_{2}$

Log likelihood value

$p$-value 
Table 6 : The Joint Markov Switching Model for Excess Returns to the Value Decile and on the Growth Decile (January 1954 to December 2007), MP As an Alternative Instrument in Modeling State Transition Probabilities

We estimate the following model for excess returns to value and growth deciles:

$$
\begin{array}{rll}
\mathbf{r}_{t} & =\boldsymbol{\beta}_{0, S_{t}}+\boldsymbol{\beta}_{1, S_{t}} T B_{t-1}+\boldsymbol{\beta}_{2, S_{t}} D E F_{t-1}+\boldsymbol{\beta}_{3, S_{t}} \Delta M_{t-2}+\boldsymbol{\beta}_{4, S_{t}} D I V_{t-1}+\boldsymbol{\epsilon}_{t} \\
\boldsymbol{\epsilon}_{t} & \sim N\left(0, \Sigma_{S_{t}}\right), \quad S_{t}=\{1,2\} \\
\log \left(\Sigma_{i i, S_{t}}\right) & =\lambda_{S_{t}}^{i} ; \quad \Sigma_{i j, S_{t}}=\rho_{S_{t}}\left(\Sigma_{i i, S_{t}}\right)^{1 / 2}\left(\Sigma_{j j, S_{t}}\right)^{1 / 2}, \quad i \neq j \\
p_{t} & =P\left(S_{t}=1 \mid S_{t-1}=1\right)=\Phi\left(\pi_{0}+\pi_{1} M P_{t-1}\right) ; \quad 1-p_{t}=P\left(S_{t}=2 \mid S_{t-1}=1\right) \\
q_{t} & =P\left(S_{t}=2 \mid S_{t-1}=2\right)=\Phi\left(\pi_{0}+\pi_{2} M P_{t-1}\right) ; \quad 1-q_{t}=P\left(S_{t}=1 \mid S_{t-1}=2\right)
\end{array}
$$

in which $\mathbf{r}_{t}=\left(r_{t}^{G}, r_{t}^{V}\right)^{\prime}$ is the vector of the monthly excess returns to the growth and value portfolios, $r_{t}^{G}$ and $r_{t}^{V}$, respectively. $\boldsymbol{\beta}_{k, S_{t}}, k=0,1,2,3,4$, is a $(2 \times 1)$ vector with elements $\boldsymbol{\beta}_{k, S_{t}}=\left(\beta_{k, S_{t}}^{G}, \beta_{k, S_{t}}^{V}\right)^{\prime}$. $\boldsymbol{\epsilon}_{t} \sim \mathcal{N}\left(0, \Sigma_{S_{t}}\right)$ is a vector of residuals. $\Sigma_{S_{t}}$ is a positive semidefinite $(2 \times 2)$ matrix containing the variances and covariances of the residuals of the value and growth portfolio excess returns in state $S_{t}$. The diagonal elements of this variance-covariance matrix, $\Sigma_{i i, S_{t}}$, take the similar form as in the univariate model: $\log \left(\Sigma_{i i, S_{t}}\right)=\lambda_{S_{t}}^{i}$. The off-diagonal elements, $\Sigma_{i j, S_{t}}$, assume a state-dependent correlation between the residuals, denoted $\rho_{S_{t}}$, i.e., $\Sigma_{i j, S_{t}}=\rho_{S_{t}}\left(\Sigma_{i i, S_{t}}\right)^{1 / 2}\left(\Sigma_{j j, S_{t}}\right)^{1 / 2}$ for $i \neq j$. TB is the one-month Treasury bill rate, $D E F$ is the yield spread between Baa- and Aaa-rated corporate bonds, $\Delta M$ is the annual rate of growth of the monetary base, and $D I V$ is the dividend yield of the value-weighted market portfolio. $M P$ is the monthly growth rate of industrial production. $\Phi$ is

\begin{tabular}{|c|c|c|c|c|c|}
\hline & Grov & wth & Value & \multicolumn{2}{|c|}{ Tests for identical asymmetries } \\
\hline & & & & \multicolumn{2}{|c|}{ Constant: $\beta_{0,1}^{G}-\beta_{0,2}^{G}=\beta_{0,1}^{V}-\beta_{0,2}^{V}$} \\
\hline Constant, state 1 & -0.053 & $(0.02)$ & $-0.043(0.02)$ & Log likelihood value & 2242 \\
\hline Constant, state 2 & 0.022 & $(0.01)$ & $0.004(0.01)$ & $p$-value & $(0.00)$ \\
\hline \multicolumn{6}{|c|}{$T B: \beta_{1,1}^{G}-\beta_{1,2}^{G}=\beta_{1,1}^{V}-\beta_{1,2}^{V}$} \\
\hline$T B$, state 1 & -6.717 & $(2.60)$ & $-10.732(2.92)$ & Log likelihood value & 2237 \\
\hline$T B$, state 2 & -2.182 & $(1.42)$ & $0.836(1.26)$ & $p$-value & $(0.00)$ \\
\hline \multicolumn{6}{|c|}{$D E F: \beta_{2,1}^{G}-\beta_{2,2}^{G}=\beta_{2,1}^{V}-\beta_{2,2}^{V}$} \\
\hline$D E F$, state 1 & 4.839 & $(1.39)$ & $7.549(1.45)$ & Log likelihood value & 2200 \\
\hline$D E F$, state 2 & -0.986 & $(0.79)$ & $-1.351(0.73)$ & $p$-value & $(0.00)$ \\
\hline \multicolumn{6}{|c|}{$\Delta M: \beta_{3,1}^{G}-\beta_{3,2}^{G}=\beta_{3,1}^{V}-\beta_{3,2}^{V}$} \\
\hline$\Delta M$, state 1 & 0.076 & $(0.10)$ & $0.133(0.11)$ & Log likelihood value & 2243 \\
\hline$\Delta M$, state 2 & 0.025 & $(0.04)$ & $-0.010(0.03)$ & $p$-value & $(0.00)$ \\
\hline \multicolumn{6}{|c|}{$D I V: \beta_{4,1}^{G}-\beta_{4,2}^{G}=\beta_{4,1}^{V}-\beta_{4,2}^{V}$} \\
\hline$D I V$, state 1 & 0.756 & $(0.59)$ & $0.104(0.23)$ & Log likelihood value & 2248 \\
\hline$D I V$, state 2 & 0.278 & $(0.58)$ & $0.513(0.22)$ & $p$-value & $(0.45)$ \\
\hline \multicolumn{6}{|l|}{ Standard deviation parameters } \\
\hline$\sigma$, state 1 & 0.061 & $(0.00)$ & $0.070(0.00)$ & & \\
\hline$\sigma$, state 2 & 0.039 & $(0.00)$ & $0.036(0.00)$ & & \\
\hline \multicolumn{6}{|c|}{ Parameters common to both deciles } \\
\hline \multicolumn{6}{|l|}{ Correlation parameters } \\
\hline$\rho$, state 1 & & 0.655 & $(0.04)$ & & \\
\hline$\rho$, state 2 & & 0.613 & $(0.04)$ & & \\
\hline \multicolumn{6}{|c|}{ Transition probability parameters } \\
\hline Constant & & 1.320 & $(0.18)$ & $: \pi_{1}=\pi_{2}$ & \\
\hline$M P$, state 1 & & -0.980 & $(0.34)$ & Log likelihood value & 2238 \\
\hline$M P$, state 2 & & -0.156 & $(0.24)$ & $p$-value & $(0.00)$ \\
\hline Unconstrained log likelihood & & 2248 & & & \\
\hline
\end{tabular}
the cumulative density function of a standard normal variable. Standard errors are in parentheses beside the estimates. The $p$-value from the likelihood ratio test is the probability of the restriction that the asymmetry between the value and growth portfolios is identical against the alternative that the asymmetry is larger for the value portfolio. 
Figure 1 : Univariate and Bivariate Markov Switching Models, Probability of the High Volatility State (January 1954 to December 2007)

We plot the time series of the probability of being in state 1 (high volatility) at time $t$ conditional on information in period $t-1$ in the univariate Markov switching model for the value portfolio (Panel A) and for the growth portfolio (Panel B). Panel C plots the time series of the probability of being in the high volatility state from the bivariate Markov switching model that estimates the expected value and growth returns jointly. The value portfolio is the high book-to-market decile and the growth portfolio is the low book-to-market decile. The portfolio return data are from Kenneth French's Web site. Shaded areas indicate NBER recession periods.

Panel A: Value, univariate

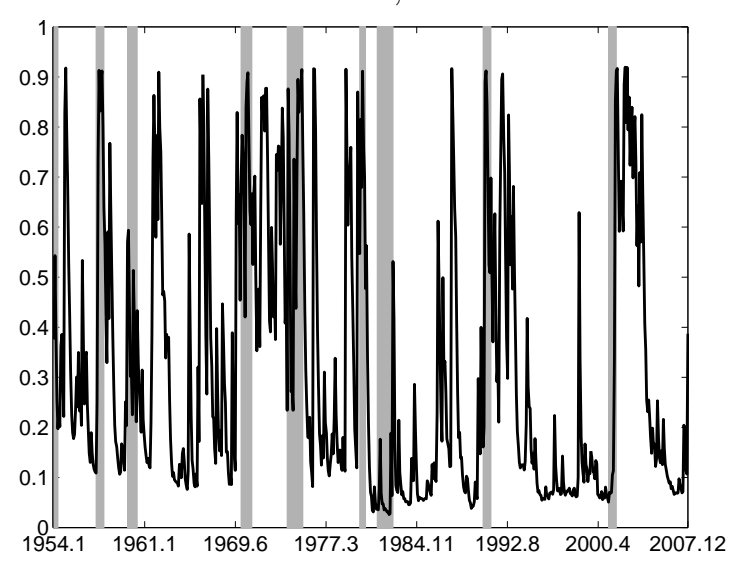

Panel B: Growth, univariate

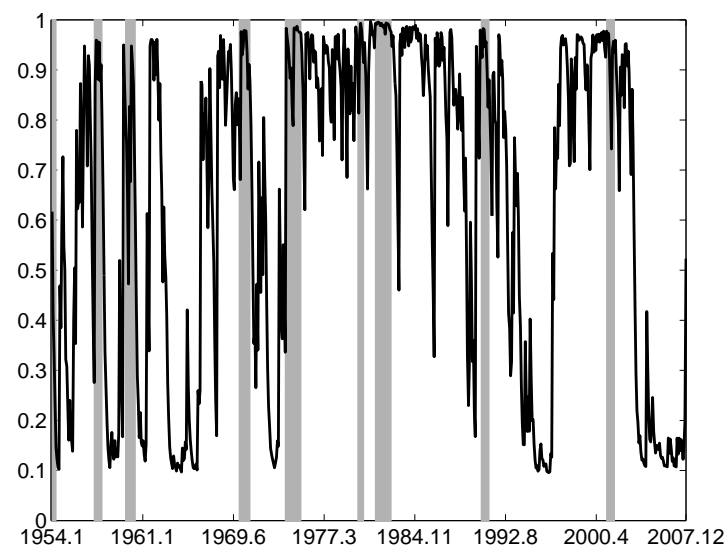

Panel C: Bivariate

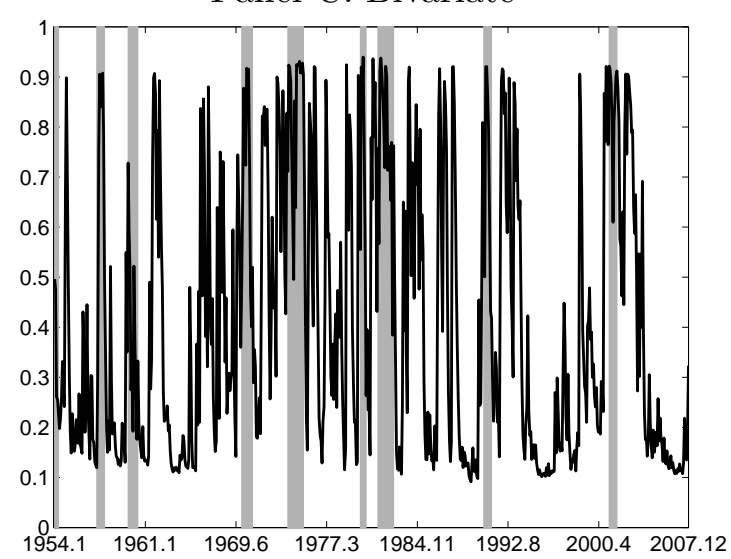


Figure 2 : Expected Excess Returns, Univariate and Bivariate Markov Switching Models (January 1954 to December 2007)

This figure plots the expected excess returns for the value portfolio (Panel A), the growth portfolio (Panel B), and their difference (Panel C) from the univariate and bivariate Markow switching models in Tables 1 and 3. The solid lines use the parameter estimates in the bivariate Markov switching model, and the dashed lines use the estimates from the univariate model. The value portfolio is the decile with the highest book-to-market equity and the growth portfolio is the decile with the lowest book-to-market equity. The portfolio return data are from Kenneth French's Web site. Shaded areas indicate NBER recession periods.

Panel A: Value

$\stackrel{\oplus}{\bullet}$
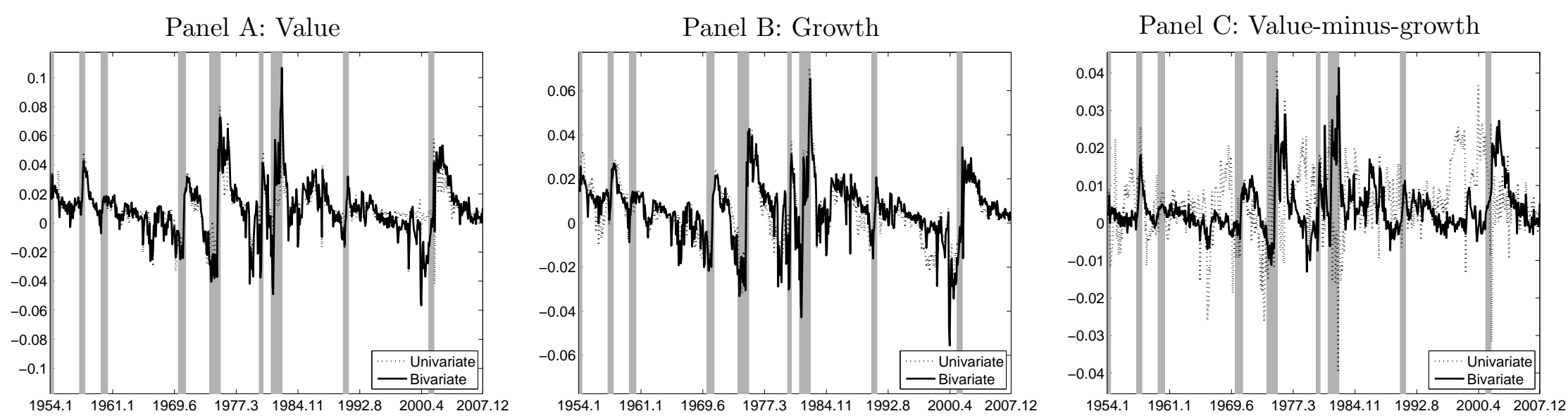


\section{Figure 3 : Bivariate Markov Switching Model, Conditional Volatilities, and Conditional}

Sharpe Ratios, Value and Growth Portfolios (January 1954 to December 2007)

Panel A plots the conditional volatilities for the value and growth portfolios. Panel B plots conditional Sharpe ratios defined as expected excess returns divided by conditional volatilities. The solid lines are for the value portfolio and the dotted lines are for the growth portfolio. The value portfolio is the decile with the highest book-to-market equity and the growth portfolio is the decile with the lowest book-to-market equity. The portfolio return data are from Kenneth French's Web site. Shaded areas indicate NBER recession periods.

Panel A: Conditional volatilities

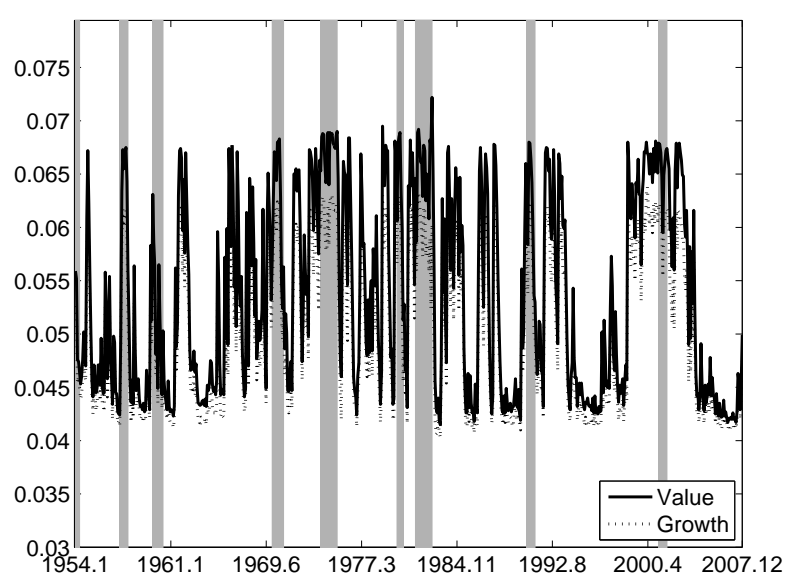

Panel B: Conditional Sharpe ratios

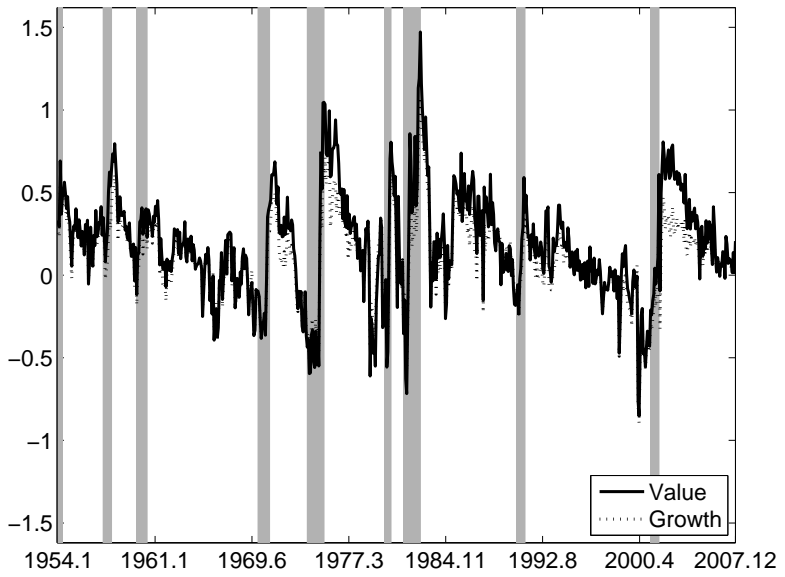


Figure 4 : Conditional Volatility and Conditional Sharpe Ratio, The Value-minus-Growth Portfolio, Univariate Markov Switching Model (January 1954 to December 2007)

For the value-minus-growth portfolio, we plot the conditional volatility (Panel A), and the conditional Sharpe ratio (Panel B) from the univariate Markow switching model. The value portfolio is the decile with the highest book-to-market equity and the growth portfolio is the decile with the lowest book-to-market equity. The portfolio return data are from Kenneth French's Web site. Shaded areas indicate NBER recession periods.

Panel A: Conditional volatility

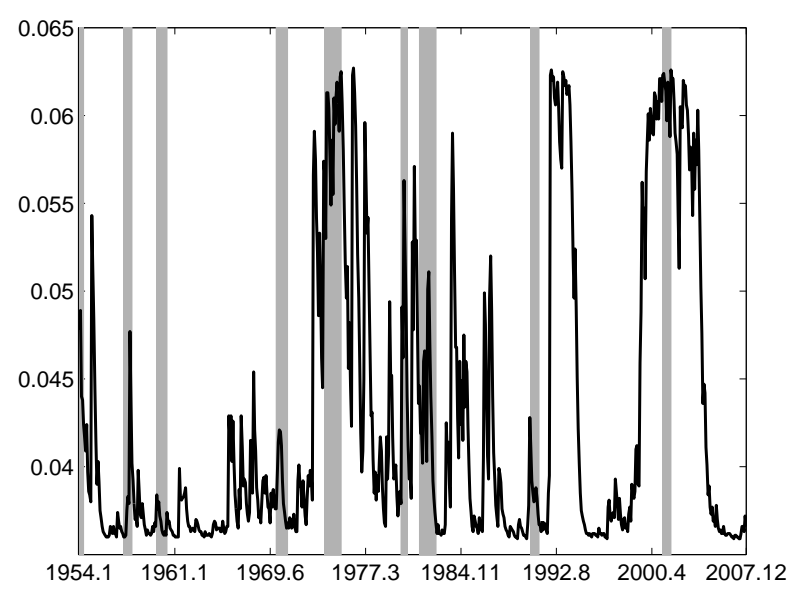

Panel B: Conditional Sharpe ratio

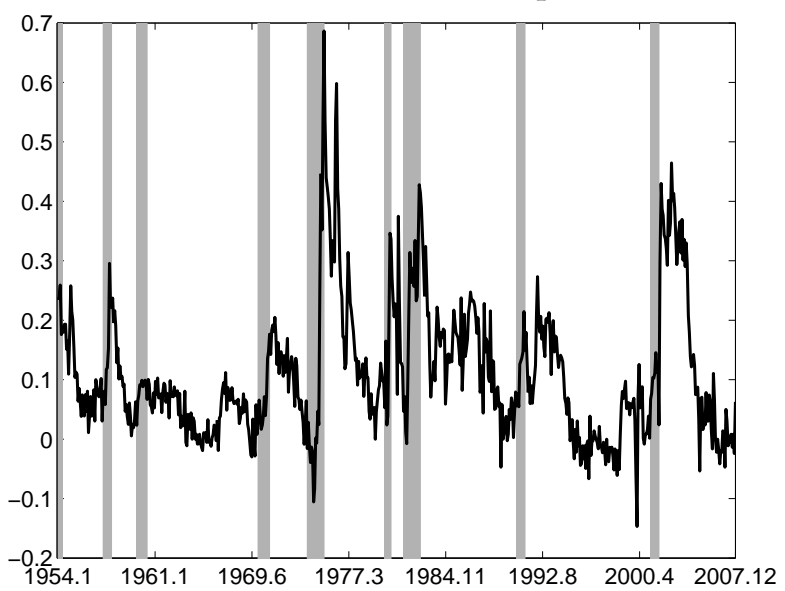


Figure 5 : Out-of-Sample Forecasts of Excess Returns, Bivariate Markov Switching Model

We plot the expected excess returns for the value portfolio (Panel A), the growth portfolio (Panel B), and their difference (Panel C) from the bivariate Markow switching model. The solid lines plot the in-sample predicted excess returns (as in Figure 2). The dashed lines plot the out-of-sample forecasts: the predicted excess returns at period $t$ are based on the parameters estimated using period $t-1$ information only. The value portfolio is the high book-to-market decile, and the growth portfolio is the low book-to-market decile. The portfolio return data are from Kenneth French's Web site. Shaded areas indicate NBER recession periods. The in-sample forecasts are from January 1954 to December 2007, and the out-of-sample forecasts are from January 1977 to December 2007.
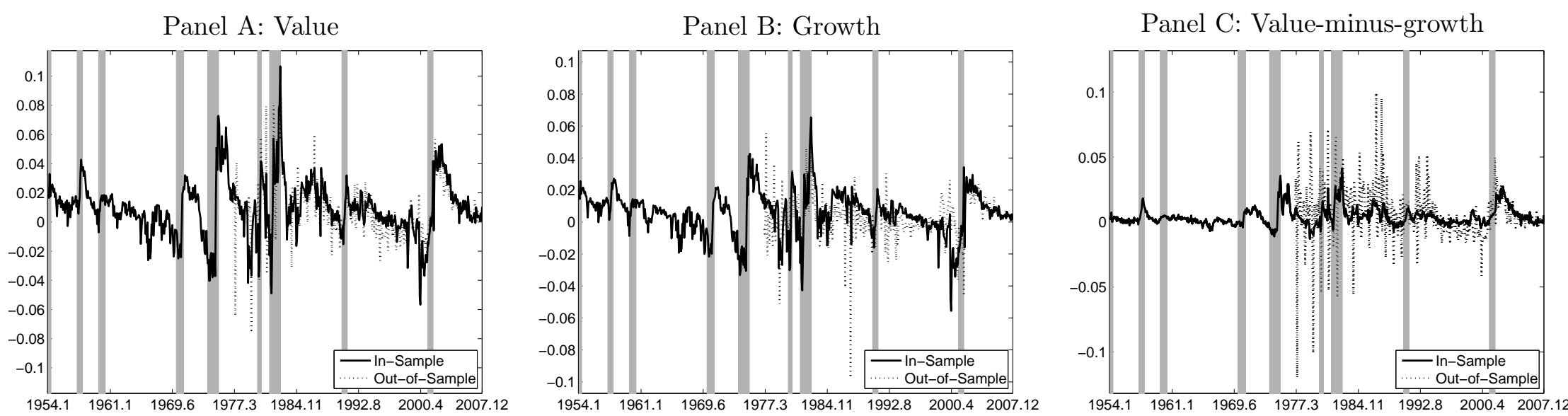
Figure 6 : The Expected Value Premiums from the Bivariate Markov Switching Model, the Linear Predictive Regression without Interacted Terms, and the Linear Predictive Regression with Interacted Terms (January 1954 to December 2007)

Panel A plots the expected value premium from the bivariate Markov switching model, defined as the difference between the expected value portfolio return and the expected growth portfolio return (the solid line). The panel also plots the expected value premium measured as the fitted component of the linear predictive regression of the realized value premium on the one-month Treasury bill, the default premium, the growth of the money stock, and the dividend yield (the dotted line). Panel B plots the expected value premium from the bivariate Markov switching model (the solid line), and the expected value premium measured as the fitted component of the linear predictive regression of the realized value premium on the one-month Treasury bill, the default premium, the growth of the money stock, and the dividend yield, as well as their interacted terms with the one-month Treasury bill rate. The value portfolio is the high book-to-market decile and the growth portfolio is the low book-to-market decile. The portfolio return data are from Kenneth French's Web site. Shaded areas indicate NBER recession periods.

Panel A: Markov versus linear regression without interacted terms

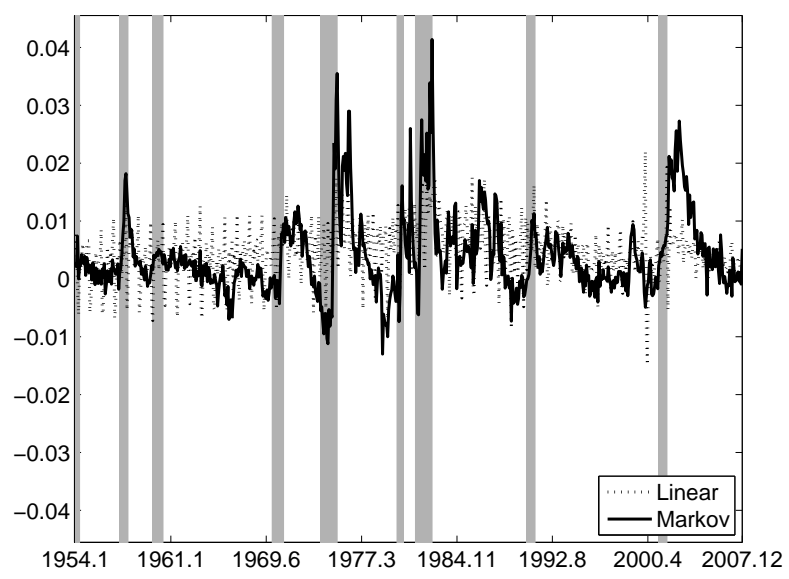

Panel B: Markov versus linear regression with interacted terms

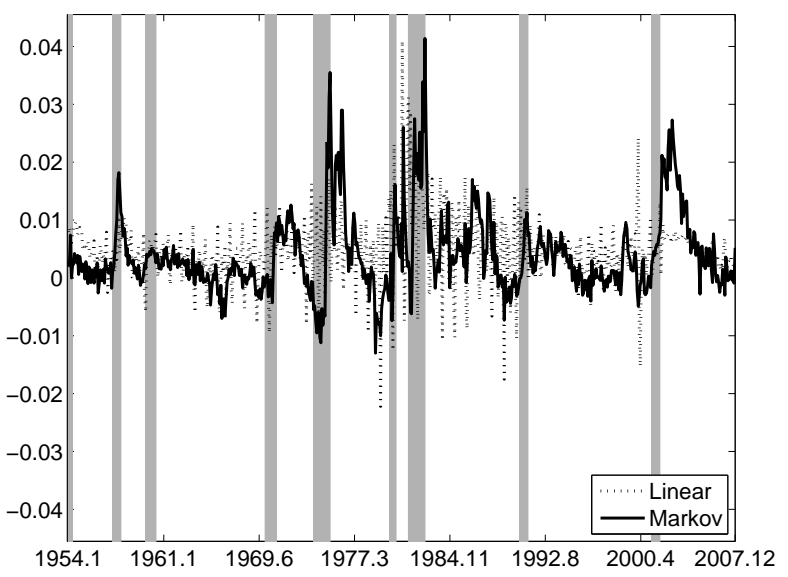

